\title{
Targeted lipid nanoparticle delivery of calcitriol to human monocyte-derived macrophages in vitro and in vivo: investigation of the anti-inflammatory effects of calcitriol
}

This article was published in the following Dove Medical Press journal:

International Journal of Nanomedicine

\author{
Aisha Rafique' \\ Anders Etzerodt ${ }^{2}$ \\ Jonas H Graversen ${ }^{3}$ \\ Søren K Moestrup 3 \\ Frederik Dagnæs-Hansen ${ }^{2}$ \\ Holger Jon Møller' \\ 'Department of Clinical Biochemistry, \\ Aarhus University Hospital, Aarhus, \\ Denmark; ${ }^{2}$ Institute of Biomedicine, \\ Aarhus University, Aarhus, Denmark; \\ ${ }^{3}$ Department of Molecular Medicine, \\ University of Southern Denmark, \\ Odense, Denmark
}

\begin{abstract}
Background: Vitamin $\mathrm{D}_{3}$ possesses anti-inflammatory and modulatory properties in addition to its role in calcium and phosphate homeostasis. Upon activation, macrophages $(\mathrm{M})$ can initiate and sustain pro-inflammatory cytokine production in inflammatory disorders and play a pathogenic role in certain cancers.

Purpose: The main purpose of this study was to encapsulate and specifically target calcitriol to macrophages and investigate the anti-inflammatory properties of calcitriol in vitro and in vivo. Methods: In this study we have designed and developed near-infrared calcitriol PEGylated nanoparticles (PEG-LNP(Cal)) using a microfluidic mixing technique and modified lipid nanoparticles (LNPs) to target the M specific endocytic receptor CD163. We have investigated LNP cellular uptake and anti-inflammatory effect in LPS-induced M in vitro by flow cytometry, confocal microscopy and gene expression analyses. LNP pharmacodynamics, bio-distribution and organ specific LNP accumulation was also investigated in mice in vivo.
\end{abstract}

Results: In vitro, we observed the specific uptake of PEG-LNP(Cal)-hCD163 in human M, which was significantly higher than the non-specific uptake of control PEG-LNP(Cal)-IgG(h) in M. Pretreatment with encapsulated calcitriol was able to attenuate intracellular TNF- expression, and M surface marker HLA-DR expression more efficiently than free calcitriol in LPS-induced $M$ in vitro. Encapsulated calcitriol diminished mRNA gene levels of TNF-, NF-B, MCP-1 and IL-6, while upregulating IL-10. TNF- and IL-6 protein secretion also decreased. In mice, an in vivo pharmacodynamic study of PEG-LNP(Cal) showed a rapid clearance of IgG and CD163 modified LNPs compared to PEG-LNP(Cal). Antibody modified PEG-LNP(Cal) accumulated in the liver, spleen and kidney, whereas unmodified PEG-LNP(Cal) accumulation was only observed in the liver.

Conclusion: Our results show that calcitriol can be effectively targeted to M. Our data confirms the anti-inflammatory properties of calcitriol and this may be a potential way to deliver high dose bioactive calcitriol to $\mathrm{M}$ during inflammation in vivo.

Keywords: macrophages, $1.25(\mathrm{OH})_{2} \mathrm{D}_{3}$, calcitriol, lipid nanoparticles, pro-inflammatory cytokines, CD163 targeted drug delivery, gene expression analyses, in vivo pharmacodynamics

\section{Introduction}

Nanoparticle drug-delivery systems are promising tools used for delivering active molecules to target sites of action in vivo, resulting in increased bioavailability and drug efficacy and minimized off-target adverse side effects. Several targeted nanoparticle drug-delivery systems have been reported in advanced trial phases for certain cancers ${ }^{1}$ and have the potential for the treatment of autoimmune disorders and inflammatory diseases such as nonalcoholic fatty-liver disease (NAFLD).,
Correspondence: Aisha Rafique Department of Clinical Biochemistry, Aarhus University Hospital, Palle-Juul Jensens Boulevard 99, 8200 Aarhus N Denmark

Tel +45 23829953

Email araf@clin.au.dk 
Macrophages (M $\varphi$ ) are important players in the pathogenesis of, for example, obesity-associated type 2 diabetes, inflammatory diseases such as nonalcoholic steatohepatitis (NASH) and rheumatoid arthritis and in certain cancers. ${ }^{4-7}$ These phagocytes are plastic, heterogenic immune cells capable of adapting, polarizing, and altering cytokine production and cell surface marker expression according to their microenvironment. ${ }^{8}$ Tumor necrosis factor-alpha (TNF- $\alpha$ ) and interleukin (IL)- 6 are inflammatory cytokines released by $\mathrm{M} \varphi$ upon endotoxin challenge ${ }^{9}$ and have been linked to insulin resistance, obesity, and chronic low-grade inflammatory disorders. ${ }^{10,11}$

Specific pro- or anti-inflammatory $\mathrm{M} \varphi$ subsets, mimicking in vivo phenotypes, can be generated by stimulation with either interferon- $\gamma$ and lipopolysaccharide (LPS) or IL-13 and IL-4 in vitro. ${ }^{12}$ In addition, $\mathrm{M} \varphi$ can also be characterized by their function as inhibitory $\mathrm{M} \varphi$ mediated by, for example, nitric oxide or as wound healing $\mathrm{M} \varphi$ by producing orthinine. ${ }^{13}$ CD163 is the hemoglobin-haptoglobin scavenger receptor and is exclusively expressed on circulating monocytes, tissue-resident $\mathrm{M} \varphi$, and tumor-associated $\mathrm{M} \varphi$. Thus, CD163 is an ideal therapeutic target for drug delivery to $\mathrm{M} \varphi$ in both inflammatory disorders and cancers. ${ }^{14-16}$

The physiological role of vitamin $\mathrm{D}_{3}$ and its metabolite in calcium/phosphate homeostasis and bone metabolism has been elucidated. ${ }^{17}$ Pre-vitamin $\mathrm{D}_{3}$ is produced in the skin and transported by vitamin D-binding protein to the liver, where it is modified by Cyp27a1 into $25(\mathrm{OH}) \mathrm{D}_{3}$. In the kidneys, Cyp27b1 converts $25(\mathrm{OH}) \mathrm{D}_{3}$ into bioactive $1,25(\mathrm{OH})_{2} \mathrm{D}_{3}$ (calcitriol) ${ }^{18}$ Besides the classical role of calcitriol, there is evidence showing that calcitriol has both immunoregulatory and anti-inflammatory properties, which influence innate and adaptive immune responses. ${ }^{7}$ Most immune cells (eg, monocytes and $\mathrm{M} \varphi,{ }^{19}$ lymphocytes, dendritic cells, ${ }^{20} \mathrm{NK}$ cells, and activated $\mathrm{T}$ and $\mathrm{B}$ cells ${ }^{21,22}$ ) express both the nuclear vitamin $\mathrm{D}$ receptor (VDR) and Cyp27b1. ${ }^{23}$ VDR, calcitriol, and the retinoic $\mathrm{X}$ receptor complex together and bind to the vitamin $\mathrm{D}$ responsive element resulting in nonclassical gene regulation of immune cell proliferation, differentiation, and apoptosis.

Vitamin D deficiency may also be associated with chronic low-grade inflammation, insulin resistance, and type 2 diabetes,${ }^{24}$ and the use of calcitriol as an anti-inflammatory and anticancer agent has been reported in a number of studies (eg, in type 2 diabetes, ${ }^{11}$ rheumatoid arthritis, ${ }^{7}$ colon cancer, ${ }^{25}$ and preclinical anticancer trials $\left.{ }^{26}\right)$. However, the risk of developing hypercalcemia prevents systemic administration. ${ }^{27} \mathrm{Chen}$ et al demonstrated that vitamin D-VDR signaling suppresses LPS-mediated inflammation by blocking nuclear factor (NF)- $\mathrm{\kappa B}$ activation and suppressing miR-155, resulting in increased SOCS1 translation and thereby enhancing negative feedback regulation of LPS-mediated inflammatory response in murine RAW 264.7 cells. ${ }^{28}$ It has been reported that VDR together with calcitriol is able to attenuate NF- $\mathrm{KB}$ transcriptional activity through the reduced degradation of $\mathrm{I} \kappa \mathrm{B} \alpha$ in co-transfected HEK-293 cells. ${ }^{29}$ Calcitriol is able to counteract the effects of FGF-23 to induce TNF- $\alpha$ in RAW 264.7 cells. ${ }^{30}$ Delivering encapsulated calcitriol to, for example, EGFR tyrosine kinase inhibitor-resistant lung cancer or to $\mathrm{M} \varphi$ involved in NASH has demonstrated effective cellular uptake and drug efficacy. 2,31

In the present study, we developed calcitriol lipid nanoparticles (LNP(Cal)) and PEGylated calcitriol lipid nanoparticles (PEG-LNP(Cal)) with a core of triolein-POPC (2-oleoyl-1-palmitoyl-sn-glycero-3-phosphocholine), as reported by Zhigaltsev et al. ${ }^{32}$ PEG-LNPs have an improved half-life and circulation time in vivo compared to conventional $\mathrm{LNPs}^{1}$ and are able to avoid rapid uptake by nontarget cells. Several studies have shown that the improved half-life of PEG-LNPs results in the increased accumulation of LNPs in tumor and inflamed areas, where increased presence of immune cells is observed in certain cancers and inflammatory diseases. ${ }^{33,34}$ In this study, we targeted PEG-LNP(Cal) to the $\mathrm{M} \varphi$ endocytic scavenger receptor CD163 using an antiCD163 monoclonal antibody ( $\mathrm{mAB}$ ) in order to investigate the specific uptake and effect of calcitriol on $M \varphi$. Specifically targeting LNPs to improve drug molecule uptake by selected cells, thereby improving drug efficacy and the therapeutic index, is a promising approach for the treatment of both cancers and immune-mediated inflammatory diseases.

\section{Materials and methods \\ Materials}

Rat anti-mouse CD163 antibody (clone: E10B10), humanized antihuman CD163 antibody (clone: KN2/ $\mathrm{NRY}$ ), denoted as $\alpha \mathrm{mCD} 163$ and $\alpha \mathrm{hCD} 163,{ }^{35}$ polyclonal rabbit-antihuman CD163 antibody, and CD163-transfected Chinese hamster ovarian $(\mathrm{CHO})$ cells $^{36}$ were produced as previously described. ${ }^{35}$ Human IgG (cat no $62-8400$ ) and DID' oil:DiIC 18 (5) oil (1,1'-dioctadecyl-3,3,3',3'tetramethylindodicarbocyanine perchlorate) (D307) were obtained from Thermo Fisher Scientific (Waltham, MA, USA). Glyceryl trioleate (triolein) (cat no T7140-1G), POPC (42773; $100 \mathrm{mg})$, rat IgG (I4131; $10 \mathrm{mg})$, brefeldin A (B6542; $5 \mathrm{mg}$ ), and saponin (47036-50G-F) were obtained from Sigma-Aldrich Co (St Louis, MO, USA). pNPPEG3400-1,2-dioleoyl-sn-glycero-3-phosphoethanolamine (DOPE) was obtained from Anders Etzerodt (Institute 
of Biomedicine, Aarhus University, Aarhus, Denmark). Calcitriol (CAS nr: 32222-06-3) was purchased from Cayman Chemical (Ann Arbor, MI, USA). PEG2000-DSPE (N-(carbonyl-methoxypolyethylene glycol-2000)-1,2distearoyl-sn-glycero-3-phosphoethanolamine, sodium salt) was obtained from Lipoid AG (Steinhausen, Switzerland). Human donor buffy coats were obtained from the Blood Bank at Aarhus University Hospital. For monocyte purification, an EasySep ${ }^{\circledR}$ Human CD14 Positive Selection Kit from StemCell Technologies (Vancouver, BC, Canada) was utilized. Human TNF- $\alpha$ (DY210-05) and human IL-6 (DY206-05) DuoSet ELISAs were obtained from R\&D Systems (Minneapolis, MN, USA). Specific antibodies for flow cytometry and confocal microscopy included the following: human CD80 HRZN V450 (clone: L307.4) was obtained from Becton Dickinson (Franklin Lakes, NJ, USA); FITC antihuman HLA-DR (clone L243) and PE-antihuman CD163 (clone: GHI) were obtained from Nordic BioSite (Taby, Sweden); wheat germ agglutinin Alexa Flour 488 (cat no W11261), Live/Dead (near-infrared stain), and antihuman TNF- $\alpha$ MAB11 EF450 were obtained from Thermo Fisher Scientific. Antihuman CD11b Bv510 (ICRF44) was obtained from BioLegend (Nordic BioSite). Charcoal stripped (CS)FBS used for the in vitro studies was obtained from Thermo Fisher Scientific. For RNA purification, QIAamp RNA Blood Mini kits were purchased from Qiagen NV (Venlo, the Netherlands). The iScript Advanced cDNA Synthesis Kit for quantitative PCR (qPCR) was obtained from Bio-Rad Laboratories Inc (Hercules, CA, USA), and LightCycler 480 SYBR Green Master Mix was obtained from Hoffman-La Roche Ltd (Basel, Switzerland).

\section{Animals}

Nine-week-old RjOrl:SWISS and C57BL/6JRj mice were supplied by Janvier-Labs (Le Genest-Saint-Isle, France) and housed at least for 1 week for acclimatization prior to the experiments at the Biomedical Animal Facility (Aarhus University, Bartholin Building). The mice were housed according to Danish legislation rules and EU Directive $2010 / 63$ on the protection of animals used for scientific purposes in groups of three to four in individually ventilated cages (Tecniplast, Buguggiate, Italy). The mice were subjected to a 12-hour light/12-hour dark schedule and were fed standard chow (Altromin \#1324, Lage, Germany) and provided tap water ad libitum throughout the experiment. The animals were given nesting material, shredded paper strips, and wooden squares as environmental enrichment. Bedding consisted of aspen wood chips from Tapvei, Finland.
At the end of the study, the mice were sacrificed by cervical dislocation. All animal studies were performed with the permission of the Danish Animal Experiments Inspectorate (J no 2014-15-0201-00377). All the animal experiments performed complied with the EU Directive (2010/63) as well as national and international legislations, including the Animal Welfare Policy at Aarhus University.

\section{Preparation of calcitriol LNPs}

LNPs were formulated using a microfluidic mixing method on a NanoAssemblr ${ }^{\circledR}$ (Precision NanoSystems, Vancouver, BC, Canada). ${ }^{32}$ Conventional LNPs \pm calcitriol (LNP(c) or $\mathrm{LNP}(\mathrm{Cal})$ were prepared from a mixture of triolein, POPC, and \pm calcitriol. Chloroform was evaporated from pNPPEG3400-DOPE to prepare PEGylated \pm calcitriol LNPs (PEG-LNP(c) or PEG-LNP(Cal)) for post-modification. The ethanol-lipid mixture consisted of POPC, triolein, calcitriol, DID, DSPE-PEG2000, and pNP-PEG3400-DOPE. The lipid composition molar ratios for all types of LNP formulations are listed in Table 1. All lipids were dissolved and vortexed in absolute EtOH. The EtOH-lipid solution was injected into the first inlet, and citrate-buffered saline (CBS) buffer ( $\mathrm{pH}$ 5.0; $5 \mathrm{mM}$ citric acid, $150 \mathrm{mM} \mathrm{NaCl}$ ) was injected into the second inlet. LNP formulations were rapidly mixed, with a flow rate ratio of 1:5 and a total flow rate of $12 \mathrm{~mL} / \mathrm{min}$. LNP formulations for antibody conjugation were dialyzed twice against CBS buffer $(\mathrm{pH} 5)$ overnight at $4^{\circ} \mathrm{C}$. Conventional LNPs were prepared in PBS and dialyzed twice against $\mathrm{PBS}(\mathrm{pH} 7.2)$ overnight at $4^{\circ} \mathrm{C}$. All LNP formulations were tested by dynamic light scattering (DLS) (Wyatt Technology Europe GmbH, Dernbach, Germany) to determine their size (radius, nM) and polydispersity. To determine encapsulation efficiency, $50 \mu \mathrm{L}$ LNP samples were analyzed by reverse phase hydrophobic chromatography using a Dionex Ultimate 3000 HPLC System (GE Healthcare Europe GmbH, Freiburg, Germany) applying an Ascentis ${ }^{\circledR} \mathrm{C} 18$ column $(10 \mathrm{~cm} \times 3 \mathrm{mM}, 3 \mu \mathrm{m})$ (Sigma-Aldrich Co), and UV absorbance at $240 \mathrm{nM}$ with the following gradient: $90 \%, 0.1 \%$ TFA in $\mathrm{H}_{2} \mathrm{O} / 10 \%, 0.1 \%$ TFA in $\mathrm{MeOH}$ to $1 \%, 0.1 \%$ TFA in $\mathrm{H}_{2} \mathrm{O} / 99 \%, 0.1 \%$ TFA in $\mathrm{MeOH}$ continued for 5 minutes.

\section{Modification of calcitriol LNPs for CDI63 targeting and surface plasmon resonance (SPR) analysis}

Targeted LNPs were produced by modification with either amCD163, ohCD163, irrelevant human IgG, or irrelevant rat IgG. Under LNP formation, the active PEG-lipid derivate 
Table I Overview of all LNP formulations with molecular weight of compounds, lipid composition molar ratio of LNPs, lipid concentration, flow rate ratios, and total flow rate applied to formulate LNPs

\begin{tabular}{|c|c|c|c|c|}
\hline & Lipid & Mw & $\begin{array}{l}\text { Lipid composition molar } \\
\text { ratio }\end{array}$ & $\begin{array}{l}\text { Lipid concentration/FRR/TFR } \\
\text { ( } \mathrm{mL} / \mathrm{min})\end{array}$ \\
\hline \multicolumn{5}{|c|}{ Conventional LNPs } \\
\hline \multirow[t]{2}{*}{ LNP(c) } & POPC & 760.067 & 33.0 & \multirow[t]{5}{*}{$(2 \mathrm{mM} / \mathrm{I}: 5 / \mathrm{I} 2)$} \\
\hline & Triolein & 885.432 & 67.0 & \\
\hline \multirow[t]{3}{*}{ LNP(Cal) } & POPC & 760.067 & 33.0 & \\
\hline & Triolein & 885.432 & 58.0 & \\
\hline & Calcitriol & 416.64 & 9.0 & \\
\hline \multicolumn{5}{|c|}{ DID-fluorescent PEGylated LNPs } \\
\hline \multirow[t]{4}{*}{ PEG-LNP(c) } & POPC & 760.067 & 29.8 & \multirow[t]{9}{*}{$(2 \mathrm{mM} / \mathrm{I}: 5 / \mathrm{I} 2)$} \\
\hline & Triolein & 885.432 & 67.0 & \\
\hline & DSPE-PEG2000 & 2,810 & 3.0 & \\
\hline & DID & 959.91 & 0.2 & \\
\hline \multirow[t]{5}{*}{ PEG-LNP(Cal) } & POPC & 760.067 & 29.8 & \\
\hline & Triolein & 885.432 & 58.0 & \\
\hline & Calcitriol & 416.64 & 9.0 & \\
\hline & DSPE-PEG2000 & 2,810 & 3.0 & \\
\hline & DID & 959.91 & 0.2 & \\
\hline \multicolumn{5}{|c|}{ DID-fluorescent PEGylated LNPs modified for mAB conjugation } \\
\hline \multirow[t]{5}{*}{ PEG-LNP(c) } & POPC & 760.067 & 29.3 & \multirow[t]{11}{*}{$(2 \mathrm{mM} / \mathrm{l}: 5 / \mathrm{I} 2)$} \\
\hline & Triolein & 885.432 & 67.0 & \\
\hline & DSPE-PEG2000 & 2,810 & 3.0 & \\
\hline & pNP-PEG3400-DOPE & $4,369.0$ & 0.5 & \\
\hline & DID & 959.91 & 0.2 & \\
\hline \multirow[t]{6}{*}{ PEG-LNP(Cal) } & POPC & 760.067 & 29.8 & \\
\hline & Triolein & 885.432 & 58.0 & \\
\hline & Calcitriol & 416.64 & 9.0 & \\
\hline & DSPE-PEG2000 & 2,810 & 3.0 & \\
\hline & pNP-PEG3400-DOPE & $4,369.0$ & 0.5 & \\
\hline & DID & 959.91 & 0.2 & \\
\hline
\end{tabular}

Abbreviations: LNP, lipid nanoparticles; LNP(Cal), conventional calcitriol LNPs; LNP(c), conventional empty LNPs; PEG, polyethylene glycol; PEG-LNP(Cal), calcitriol PEGylated lipid nanoparticles; Mw, molecular weight; FRR, flow rate ratio; TFR, total flow rate; mAB, monoclonal antibody.

pNP-PEG3000-DOPE, synthesized as described by Torchilin et al, ${ }^{37}$ was incorporated into the surface of the LNPs $(0.5 \%$ of the total lipid). The antibody insertion reaction was $\mathrm{pH}$ dependent and performed by mixing the LNP formulation (pH 5.0), protein $1.3 \mathrm{mg} / \mathrm{mL}$ (molar ratio 1,000:1), and adding borate-buffered saline ( $\mathrm{pH} 8.5$; boric acid $100 \mathrm{mM}$, $\mathrm{NaCl} 150 \mathrm{mM}$, sodium tetraborate $25 \mathrm{mM}$ ). The reaction was incubated overnight at $4^{\circ} \mathrm{C}$ following dialysis twice against PBS (pH 7.2) at $4^{\circ} \mathrm{C} . .^{37,38}$ Total protein concentration was measured using a Pierce BCA protein micro assay (Thermo Fisher Scientific). SPR analyses were conducted to test PEG-LNP(Cal)- $\alpha \mathrm{CD} 163$ binding to human or murine CD163 using a Biacore 3000 instrument (Biacore, Uppsala, Sweden). ${ }^{39}$ Biacore sensor chips were activated with
N-ethyl-N'-(3-dimethylaminopropyl) carbodiimide and $0.05 \mathrm{M}$ N-hydroxysuccinimide. Recombinant human and murine CD163 were immobilized in $10 \mathrm{mM}$ sodium acetate (pH 4.0), and the remaining binding positions were blocked by $1 \mathrm{M}$ ethanolamine $(\mathrm{pH} 8.5)$. The attachment procedure resulted in immobilized $0.0483 \mathrm{pmol}$ human $\mathrm{CD} 163 / \mathrm{mm}^{2}$ and murine $\mathrm{CD} 163 / \mathrm{mm}^{2}$ in the range of $0.01-0.05 \mathrm{pmol}$ murine CD163/ $\mathrm{mm}^{2}$. LNP samples were tested in three different concentrations (total antibody), 5, 2.5, and $1.25 \mu \mathrm{g} / \mathrm{mL}$, including a control antibody with CaHBS running buffer (10 mM Hepes, $150 \mathrm{mM} \mathrm{NaCl}, 3 \mathrm{mM} \mathrm{Ca}_{2} \mathrm{Cl}_{2}+0.05 \%$ Tween 20, $\mathrm{pH}$ 7.4). The flow cells were regenerated with $500 \mathrm{mM}$ phosphoric acid ( $\mathrm{pH} 1.3$ ), and data were analyzed using the Biomolecular Interaction Analysis evaluation program. 


\section{Purification of human mononuclear cells from buffy coats}

Buffy coats from healthy donors were diluted with $0.9 \%$ $\mathrm{NaCl}$, layered on to a Histopaque ${ }^{\circledR}-1077$ (Sigma-Aldrich Co), and centrifuged at $400 \times g$ at room temperature (RT) for 30 minutes without brake. The opaque interface containing mononuclear cells was added to wash buffer containing EDTA (D-PBS/2\% FBS/1 mM EDTA), gently aspirated, and centrifuged at $200 \times g$ for 10 minutes at RT without brake. The monocytes were purified using an EasySep ${ }^{\circledR}$ Human CD14 Positive Enrichment kit (cat no 18058) and a Silver EasySep ${ }^{\circledR}$ Magnet (cat no 18001). Mononuclear cell suspensions were prepared at a concentration of $5 \times 10^{7}$ cells $/ \mathrm{mL}$ in D-PBS $/ 2 \%$ FBS/1 mM EDTA. Purification of the monocytes was performed following the EasySep ${ }^{\circledR}$ protocol. The monocytes were resuspended in RPMI 1640/penstrep/10\% FBS/100 ng/mL macrophage colony-stimulating factor $/ 10 \mathrm{ng} / \mathrm{mL}$ granulocyte-macrophage colony-stimulating factor for $\mathrm{M} \varphi$ differentiation. The cell cultures were incubated at $37^{\circ} \mathrm{C}$ under a humidified atmosphere of $95 \%$ air and $5 \% \mathrm{CO}_{2}$. All monocyte/M $\varphi$ cell cultures were supplemented with fresh medium every second day, and fully differentiated $\mathrm{M} \varphi$ were ready for in vitro studies after a 6-day incubation period.

\section{In vitro $M \varphi$ setups}

Fully differentiated $\mathrm{M} \varphi\left(1 \times 10^{6} \mathrm{M} \varphi \mathrm{s} / \mathrm{mL}\right)$ were seeded in sixwell plates for 24 hours. Prior to stimulation, the cell culture medium was replaced with RPMI/PS/10\% CS-FBS, and M $\varphi$ were incubated with calcitriol, LNP(Cal), PEG-LNP(Cal), PEG-LNP(Cal)-IgG, and PEG-LNP(Cal)- $\alpha \mathrm{hCD} 163$ for 24 hours at $37^{\circ} \mathrm{C}$ in $5 \% \mathrm{CO}_{2} / 95 \%$ air, following LPS challenge ( $1 \mu \mathrm{g} / \mathrm{mL}$ LPS for 4 hours). A total of $10 \mu \mathrm{M}$ dexamethasone for 24 hours was used as the positive control. M $\varphi$ were harvested with pre-warmed lidocaine buffer (PBS/0.5\% $\mathrm{BSA} / 5 \mathrm{mM}$ EDTA $/ 4 \mathrm{mg} / \mathrm{mL}$ lidocaine) for flow cytometry and in RNeasy lysis buffer buffer with $\beta$-mercaptoethanol (Qiagen NV) for RNA purification.

\section{Flow cytometry}

To evaluate cellular uptake and the effect of encapsulated calcitriol, $\mathrm{M} \varphi$ were incubated with DID-fluorescent PEG-LNP(Cal), PEG-LNP(Cal)-IgG, and PEG-LNP(Cal)ahCD163 ranging from 0.5 to $100 \mathrm{nM}$ for 24 hours (RPMI $1640 /$ penstrep $/ 10 \% \mathrm{CS}-\mathrm{FBS}$ at $37^{\circ} \mathrm{C}, 5 \% \mathrm{CO}_{2} / 95 \%$ air). The culture medium was collected and $\mathrm{M} \varphi$ were detached using lidocaine buffer (PBS/0.5\% BSA $/ 5 \mathrm{mM}$ EDTA $/ 4 \mathrm{mg} / \mathrm{mL}$ lidocaine from Sigma-Aldrich $\mathrm{Co}$ ) following washing steps with $\mathrm{PBS} / 0.5 \% \mathrm{BSA} / 0.09 \% \mathrm{NaN}_{3}(\mathrm{pH} 7.4$ ). To evaluate the
$\mathrm{M} \varphi$ surface marker expression of HLA-DR and CD80, M $\varphi$ were incubated with the above-mentioned LNP constructs following $1 \mu \mathrm{g} / \mathrm{mL}$ LPS challenge. $\mathrm{M} \varphi$ were harvested and blocked for unspecific antibody binding with $100 \mu \mathrm{g} /$ $\mathrm{mL}$ human IgG for 15 minutes. For uptake and surface marker expression evaluation, cells were stained with allophycocyanin-Live/Dead, PE-antihuman CD163 GHI, FITC-antihuman HLA-DR, and V450 antihuman CD80 for 30 minutes at $4{ }^{\circ} \mathrm{C}$ in the dark. M $\varphi$ were washed with D-PBS ( $\mathrm{pH} 7.4$; with $0.5 \% \mathrm{BSA}, 0.09 \% \mathrm{NaN}_{3}$ ) and resuspended in $0.9 \%$ formaldehyde. Anti-mouse Ig, $\chi /$ negative control BSA compensation plus beads (BD Biosciences, San Jose, CA, USA) for all stains, and Live/Dead, ArC ${ }^{\text {TM }}$ Amine Reactive Compensation Beads (Thermo Fisher Scientific) were prepared for compensation. Samples were analyzed using a Beckmann Coulter Navios Flow Cytometer (Brea, CA, USA). FlowJo for Macintosh software version 10.4.1 (Ashland Inc, Covington, KY, USA) was used for data analysis.

\section{RNA extraction and gene expression analysis by qPCR}

To investigate the effect of encapsulated calcitriol on pro- and anti-inflammatory cytokine mRNA gene expression, RNA was extracted using QIAamp RNA Blood Mini kits (Qiagen NV) according to the manufacturer's protocol. First, $100 \mathrm{ng}$ of total RNA was transcribed into cDNA using the following mix: $\mathrm{MgCl}_{2}$ solution $25 \mathrm{mM}, 10 \times$ PCR buffer, Oligo $50 \mu \mathrm{M}$, RNAse inhibitor, RT enzyme, and Ultrapure dNTP mix (Thermo Fisher Scientific). RT-qPCR reactions were run in duplicates containing SYBR Green I Master Mix (HoffmanLa Roche), $\mathrm{ddH}_{2} \mathrm{O}$, and target forward/reverse primers, under the following conditions: preincubation at $95^{\circ} \mathrm{C}$ for $10 \mathrm{~min}-$ utes followed by cycled amplification at $95^{\circ} \mathrm{C}$ for 10 seconds, with primer-dependent annealing temperature for 20 seconds, and $72^{\circ} \mathrm{C}$ for 5 seconds for 50 cycles. RT-qPCR was carried out using a LightCycler ${ }^{\circledR} 480$ instrument. (Hoffman-La Roche). NormFinder ${ }^{\circledR}$ software was used to determine the stable housekeeping gene. ${ }^{40}$ The relative mRNA concentration in each sample was calculated by using the second derivative max method. The target gene expression level of each sample was divided by the associated housekeeping gene GAPDH expression level. The mRNA ratios of the target gene/housekeeping gene were normalized to the untreated control. All primers and annealing temperatures are listed in Table 2.

\section{ELISA for the detection of TNF- $\alpha$ and IL- 6}

To evaluate TNF- $\alpha$ and IL- 6 protein secretion in cell culture supernatants after treatment with calcitriol LNPs we used the 
Table 2 Forward and reverse primers for RT-quantitative PCR

\begin{tabular}{|c|c|c|}
\hline $\begin{array}{l}\text { Target } \\
\text { genes }\end{array}$ & 5'-Sequence-3' & $\begin{array}{l}\text { Annealing } \\
\text { Tm }\end{array}$ \\
\hline \multirow[t]{2}{*}{$\beta$-Actin } & GGCGGCACCACCATGTACCCT & \multirow[t]{2}{*}{$68^{\circ}$} \\
\hline & AGGGGCGGACTCGTCAACT & \\
\hline \multirow[t]{2}{*}{$B 2 M$} & TACTCCAAAGATTCAGGTTTACTC & \multirow[t]{2}{*}{$64^{\circ}$} \\
\hline & TTCACACGGCAGGCATAC & \\
\hline \multirow[t]{2}{*}{ GAPDH } & TGATGACATCAAGAAGGTGGTGAAG & \multirow[t]{2}{*}{$68^{\circ}$} \\
\hline & TCCTTGGAGGCCATGTGGGCCAT & \\
\hline \multirow[t]{2}{*}{ SDHA } & TGGGAACAAGAGGGCATCTG & \multirow[t]{2}{*}{$62^{\circ}$} \\
\hline & CCACCACTGCATAAATTCATG & \\
\hline \multirow[t]{2}{*}{$T N F-\alpha$} & TGGCGTGGAGCTGAGAGA & \multirow[t]{2}{*}{$65^{\circ}$} \\
\hline & GCAATGATCCCAAAGTAGACCT & \\
\hline \multirow[t]{2}{*}{ IL-6 } & ACAGCCACTCACСТСTTC & \multirow[t]{2}{*}{$60^{\circ}$} \\
\hline & AAGTCTCCTCATTGAATCCAG & \\
\hline \multirow{2}{*}{$\begin{array}{l}N F-\kappa B \\
(p / 05)\end{array}$} & CTGGAAGCACGAATTGACAGA & \multirow[t]{2}{*}{$62^{\circ}$} \\
\hline & TGAGGTCCATCTCCTTGGTC & \\
\hline \multirow[t]{2}{*}{ IL-10 } & GCCTAACATGCTTCGAGATC & \multirow[t]{2}{*}{$62^{\circ}$} \\
\hline & TGATGTCTGGGTCTTGGTTC & \\
\hline \multirow[t]{2}{*}{$M C P-I$} & AGGGCTCGCTCAGCCAGATGC & \multirow[t]{2}{*}{$68^{\circ}$} \\
\hline & ACCACTTCTGCTTGGGGTCAGC & \\
\hline \multirow[t]{2}{*}{$C D / 63$} & ACATAGATCATGCATCTGTCATTTG & \multirow[t]{2}{*}{$62^{\circ}$} \\
\hline & САTTCTCСTTGGAATCTCAGTTCTA & \\
\hline
\end{tabular}

Abbreviations: RT, reverse transcriptase; TNF- $\alpha$, tumor necrosis factor-alpha; MCP-I, monocyte chemoattractant protein; NF, nuclear factor; IL, interleukin; Tm, temperature.

ELISA technique according to the manufacturer's standard protocol. In brief, all reagents and recombinant human TNF- $\alpha$ standards were prepared at RT following the manufacturer's instructions. To detect TNF- $\alpha$ in cell culture supernatants, microtiter well plates were prepared with $100 \mu \mathrm{L}$ of diluted capture antibody $(4.0 \mu \mathrm{g} / \mathrm{mL})$ and incubated overnight at RT. Plates were washed three times with $400 \mu \mathrm{L}$ wash buffer $\left(0.05 \%\right.$ Tween $^{\circledR}$ in PBS, pH 7.2-7.4), blocked with $300 \mu \mathrm{L}$ Reagent Diluent (1\% BSA in PBS, $\mathrm{pH}$ 7.2-7.4) and incubated for 1 hour at RT. The microtiter wells were washed again with wash buffer and $100 \mu \mathrm{L}$ of sample or standards in Reagent Diluent were added following incubation for 2 hours at RT. After incubation, the wells were washed and $100 \mu \mathrm{L}$ of detection antibody $(50 \mathrm{ng} / \mathrm{mL})$ diluted in Reagent Diluent was added followed by 2-hour incubation at RT. The wash steps were repeated, and the wells were incubated with $100 \mu \mathrm{L}$ streptavidin-horseradish peroxidase (1:40 dilution) for 20 minutes in the dark. A stop solution $\left(2 \mathrm{~N} \mathrm{H}_{2} \mathrm{SO}_{4}\right)$ was added to each well and gently mixed. Optical density was determined using a microplate reader at $540 \mathrm{nM}$. To investigate IL-6 release in the cell culture supernatant, microtiter well plates were prepared with $100 \mu \mathrm{L}$ of diluted capture antibody $(2.0 \mu \mathrm{g} / \mathrm{mL})$ and incubated overnight at RT. The same procedure described above was applied for the detection of IL-6 in the cell culture supernatants.

\section{Confocal microscopy}

To investigate the cellular uptake of targeted PEG-LNP(Cal), fully differentiated $\mathrm{M} \varphi$ were allowed to settle on chambered coverslips $\left(5 \times 10^{4}\right.$ cells/chamber) pre-coated with $100 \mu \mathrm{g} / \mathrm{mL}$ poly-D-lysine. To investigate uptake specificity, human and murine CD163-transfected CHO cells and control MOCK $\mathrm{CHO}$ cells were allowed to settle on chambered coverslips in serum-free HyClone CCM5 medium ( \pm hygromycin and mycin). M $\varphi, \mathrm{CD} 163$-transfected $\mathrm{CHO}$ cells, and control CHO cells were incubated with $25 \mathrm{nM}$ of targeted PEGLNP(Cal) and targeted PEG-LNP(c) for 24 hours. M $\varphi$ were washed and fixed with $4 \%$ paraformaldehyde in PBS (pH 7.4). Coverslips were incubated with wheat germ agglutinin 488 conjugate $(5 \mu \mathrm{g} / \mathrm{mL}$ in Hank's balanced salt solution, $1 \%$ BSA) for 10 minutes, washed with PBS, and counterstained with ProLong Gold mounting medium containing DAPI for identification of the cell nucleus. All images were captured on an Olympus Fluoview FV1000 confocal microscope (Olympus Corporation, Tokyo, Japan) at The Flow Cytometry and Confocal Microscopy Core Facility (The University of Southern Denmark, Odense, Denmark).

\section{In vivo imaging and biodistribution}

To investigate the biodistribution and tissue uptake of DID PEG-LNP(Cal) and targeted DID PEG-LNP(Cal) in vivo, SWISS mice ( $\mathrm{n}=1$ /group) were injected intravenously (IV) with an LNP solution $\left(0.05-0.1 \mathrm{mg} / \mathrm{kg} 1.25(\mathrm{OH})_{2} \mathrm{D}_{3}\right)$. The animals were anesthetized with 3.75\% isoflurane (IsoFlo Vet; Orion Pharma, Espoo, Finland) and scanned in a Xenogen IVIS ${ }^{\circledR}$ Spectrum in vivo imaging system (PerkinElmer Inc, Waltham, MA, USA) equipped with filters for ex680/em700 visualization. The system was used to measure LNP accumulation at $15,45,90,150$, and 210 minutes postinjection.

\section{Pharmacodynamic study}

To evaluate the clearance of encapsulated calcitriol in vivo, healthy C57BL/6 mice ( $\mathrm{n}=4$ /group) were injected in the tail vein with either saline water, DID PEG-LNP(Cal), DID PEGLNP(Cal)-IgG, or DID PEG-LNP(Cal)- $\alpha \mathrm{mCD} 163(0.1 \mathrm{mg} /$ $\mathrm{kg}$ calcitriol). The first blood sample (tongue blood) was collected 1 minute after injection. Multiple blood samples were collected from the tail vein at $\mathrm{T}=30$ minutes, $\mathrm{T}=1,2,4,6$, and 24 hours after intravenous injection in $20 \mu \mathrm{L} \mathrm{Na-heparinized}$ pipettes (Vitrex Medical A/S, Herlev, Denmark). All blood 
samples were imaged using the Xenogen IVIS ${ }^{\circledR}$ Spectrum in vivo imaging system and analyzed using the Living Image software version 4.5.5 (PerkinElmer Inc). To investigate tissue distribution and LNP accumulation, ex vivo imaging was performed on the liver, spleen, and kidney for all mice.

\section{Statistical analysis}

Graph Pad Prism 7 software (GraphPad Software Inc, La Jolla, CA, USA) was used to prepare graphs and to perform statistical analyses. We used a repeated measures one-way ANOVA analysis and Dunnett's multiple comparisons test to compare the means of IgG-targeted and CD163-targeted calcitriol LNPs with the mean of non-targeted calcitriol LNPs. To analyze the dose-dependent effect of calcitriol and targeting efficiency, we used a two-way repeated measures (RM) ANOVA along with Tukey's multiple comparisons test. To analyze the pharmacodynamic and LNP clearance efficiency of the non-targeted and targeted LNPs, a two-way RM ANOVA combined with Tukey's multiple comparisons test was performed. All error bars are represented as SD and significance is indicated as $* P \leq 0.05, * * P \leq 0.01, * * * P \leq 0.001$, and $* * * * P \leq 0.0001$.

\section{Results}

\section{Vitamin $D_{3}$ encapsulation efficiency and binding analysis of anti-CD 163 antibody-modified LNPs}

The size distribution of LNP(Cal) and PEG-LNP(Cal) was in the range of 30-35 $\mathrm{nM}$ radius, as measured using the DLS technique. The LNP(c) and PEG-LNP(c) mean particle radii were in the range of 35-45 nM (Figure 1A and B). Particle size distribution of $\mathrm{PEG}-\mathrm{LNP}(\mathrm{Cal})$ prior to modification is shown in Figure 1C. The LNP mean particle radius was in the range of 50-60 $\mathrm{nM}$ post-IgG and anti-CD163 mAB modification (data not shown). Total calcitriol entrapment was determined by reverse phase HPLC and LNP(Cal) and PEG-LNP(Cal) were measured at 0.056 and $0.043 \mathrm{mg} / \mathrm{mL}$, respectively, resulting in an encapsulation efficiency of $58 \%-76 \%$ of the total calcitriol input. SPR analysis was performed to study the binding of human and murine PEGLNP(Cal)- $\alpha$ CD163 to immobilized CD163 protein. Free $\alpha \mathrm{CD} 163 \mathrm{mAB}$ was used as a positive control to evaluate specific binding affinity. We observed efficient binding of PEG-LNP(Cal)- $\alpha$ hCD163 or PEG-LNP(Cal)- $\alpha$ mCD163 in contrast to no binding of LNPs modified with either irrelevant human IgG or rat IgG (Figure 1D and E). Stability studies showed that LNP formulations were stable for at least 50 days when stored at $5^{\circ} \mathrm{C}$ and $26^{\circ} \mathrm{C}$, with no change in size and polydispersity. LNP storage at $40^{\circ} \mathrm{C}$ showed that around day
50, LNP size and polydispersity increased, probably due to particle aggregation (data not shown).

\section{Cellular uptake and specificity of CDI63- targeted LNPs vs unmodified LNPs}

To assess the CD163-mediated cellular uptake of targeted PEG-LNP(Cal) and PEG-LNP(c), human M $\varphi$ were treated with non-targeted IgG and CD163-targeted DID PEGLNP(Cal) for 24 hours. LNP uptake was investigated by flow cytometry, and histograms revealed a heterogenic expression of CD163 in control $\mathrm{M} \varphi$ (Figures 2A and S1A). We observed an increased uptake of DID-PEG-LNP(Cal)$\alpha$ hCD163 by $\mathrm{M} \varphi$. In contrast, we observed modest uptake of DID-PEG-LNP(Cal) and DID-PEG-LNP(Cal)-IgG by $\mathrm{M} \varphi$. Targeted calcitriol LNPs were most likely internalized via CD163; however, DID-PEG-LNP(Cal) may have been taken up by phagocytic $\mathrm{M} \varphi$ and PEG-LNP(Cal)-IgG may be internalized through the surface Fc-receptor. Further, as reported by Etzerodt et al, our data suggest that PEGLNP(Cal)- $\alpha$ hCD163 was specifically endocytosed through CD163 in $\mathrm{M} \varphi .{ }^{35}$ CD163-mediated cellular uptake was also visualized using confocal microscopy. Human $\mathrm{M} \varphi$, human and murine CD163-transfected CHO cells, and CHO-MOCK control cells were treated with $25 \mathrm{nM}$ of IgG- and CD163targeted DID PEG-LNP(Cal) for 24 hours. We observed increased uptake of PEG-LNP(Cal)- $\alpha$ hCD163 and PEGLNP(c)- $\alpha$ CD163 (Figures 2B and S1B) in M $\varphi$ compared to the uptake of irrelevant PEG-LNP(Cal)-IgG and PEG$\mathrm{LNP}(\mathrm{c})-\mathrm{IgG}$ in $\mathrm{M} \varphi$. In contrast, we observed no uptake of PEG-LNP(Cal)-IgG in CHO-CD163(h) cells, but uptake of PEG-LNP(Cal)- $\alpha$ CD163 in CHO-CD163(h) cells. In addition, there was no uptake of either PEG-LNP(Cal)- $\alpha$ CD163 or PEG-LNP(Cal)-IgG in CHO-MOCK cells. This indicates that the uptake was CD163 specific and confirms that PEGLNP(Cal)- $\alpha$ CD163 is internalized through CD163. Similarly, we observed specific uptake of PEG-LNP(Cal)- $\alpha$ CD163 in CHO-CD163 murine cells and no uptake of PEG-LNP(Cal)IgG in CHO-CD163 murine cells (Figure S1C). Furthermore, CHO-MOCK cells (m) did not take up PEG-LNP(Cal)-IgG and PEG-LNP(Cal)- $\alpha$ CD163. Similar observations apply to the uptake of IgG- and CD163-targeted PEG-LNP(c) in CHO-CD163 and CHO-MOCK murine cells (Figure S2C).

\section{Effects of encapsulated calcitriol on pro- inflammatory cytokines and chemokines in $M \varphi$}

To examine the anti-inflammatory effects of calcitriol, $\mathrm{M} \varphi$ were incubated with non-targeted PEG-LNP(Cal) and 
A

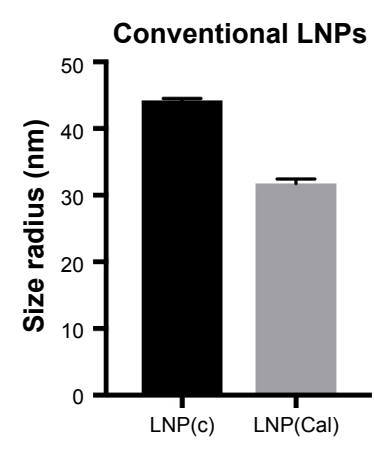

B

PNP-PEG3400-DOPEI C DSPE-PEG2000-

modified LNP

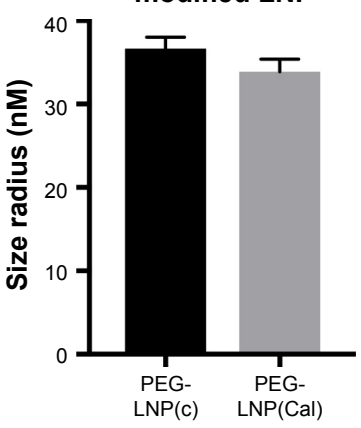

\section{C}

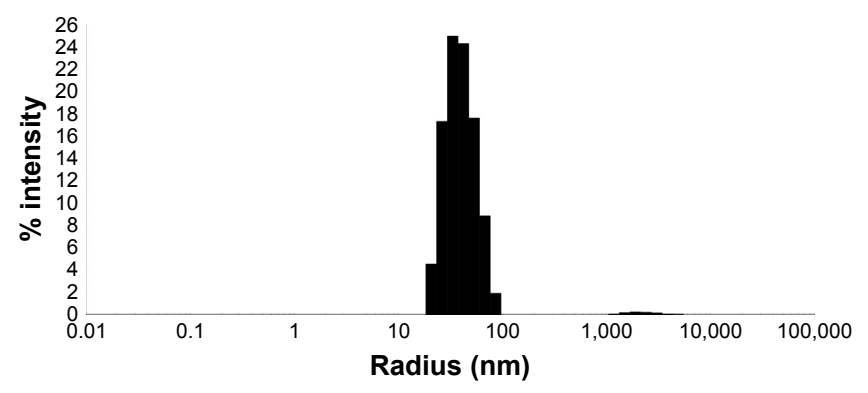

E

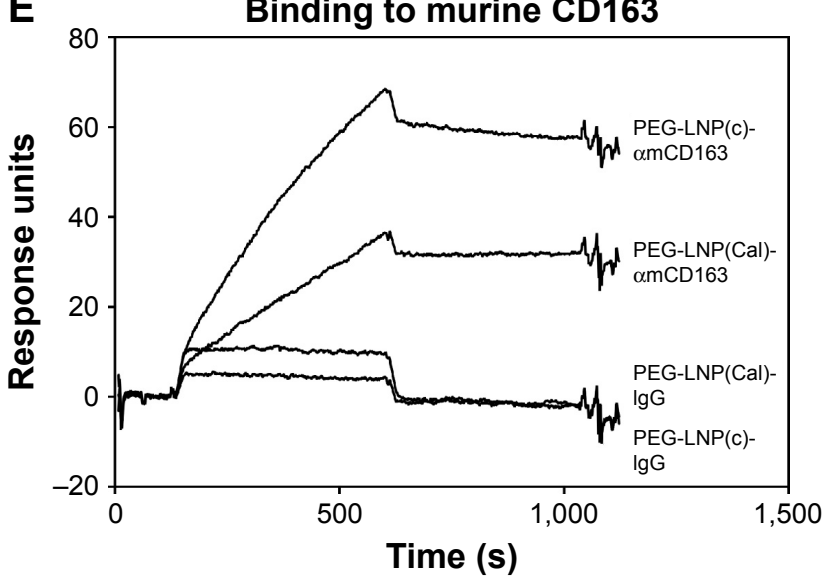

Figure I Particle size distribution and SPR analysis of PEG-LNP(Cal)-CDI63 and PEG-LNP(Cal)-lgG. (A) Mean particle radius (nm) of conventional LNP(c) (n=5) and LNP(Cal) $(n=6)$ measured on DLS. (B) Mean particle radius $(n m)$ of PEG-LNP(c) $(n=2)$ and PEG-LNP(Cal) ( $n=6)$. (C) Histogram of PEG-LNP(Cal). (D) SPR analysis of LNPAB affinity. Binding of PEG-LNP(c)- $\alpha$ hCDI63 $(5 \mu \mathrm{g} / \mathrm{mL})$, PEG-LNP(Cal)- $\alpha \mathrm{hCDI} 63(5 \mu \mathrm{g} / \mathrm{mL})$, PEG-LNP(Cal)-lgG (5 $\mu \mathrm{g} / \mathrm{mL})$, and PEG-LNP(c)-lgG (5 $\mu \mathrm{g} / \mathrm{mL})$ to immobilized human CDI63 on a Biacore CM5-sensor chip. Binding of CDI63-targeted LNPs was observed. No binding of irrelevant human lgG-modified LNPs was observed. (E) Binding of PEG-LNP(c)- $\alpha \mathrm{mCD} 163(5 \mu \mathrm{g} / \mathrm{mL})$, PEG-LNP(Cal)- $\alpha \mathrm{mCD} 163(5 \mu \mathrm{g} / \mathrm{mL})$, PEG-LNP(Cal)-lgG (5 $\mu \mathrm{g} / \mathrm{mL})$, and PEG-LNP(c)-lgG (5 $\mu \mathrm{g} / \mathrm{mL})$ to immobilized murine CDI63. Similar binding properties were observed for $\alpha \mathrm{mCD}$ 163-modified LNPs. No binding of rat lgG-modified LNPs to the sensor chip was observed.

Abbreviations: LNPs, lipid nanoparticles; LNP(Cal), conventional calcitriol LNPs; LNP(c), conventional empty LNPs; PEG, polyethylene glycol; PEG-LNP(Cal), calcitriol PEGylated lipid nanoparticles; DLS, dynamic light scattering; SPR, surface plasmon resonance; $A B$, antibody.

targeted PEG-LNP(Cal) for 24 hours prior to a 4-hour LPS challenge, followed by mRNA analysis of NF- $\kappa B$, TNF- $\alpha$, monocyte chemoattractant protein (MCP)-1, IL-6, and IL-10 gene expression. Both PEG-LNP(Cal) and targeted PEG$\mathrm{LNP}(\mathrm{Cal})$ efficiently reduced NF- $\mathrm{KB}, \mathrm{TNF}-\alpha, \mathrm{MCP}-1$, and IL-6 mRNA gene expression in a dose-dependent manner (Figure 3A-D). However, since we observed effective uptake of CD163-targeted PEG-LNP(Cal) by $\mathrm{M} \varphi$, we expected increased inhibition of pro-inflammatory markers by targeted treatment. Both PEG-LNP(Cal) and targeted PEG-LNP(Cal) upregulated IL-10 mRNA gene expression in LPS-treated $\mathrm{M} \varphi$ (Figure 3E), although this was not as effective as the positive glucocorticoid control, dexamethasone (Figure S2A-F). In addition, CD163 mRNA gene expression was not affected by pretreatment with either PEG-LNP(Cal) or targeted PEGLNP(Cal) (Figure 3F). Since TNF- $\alpha$ and IL-6 are considered as highly important markers in inflammation because they are involved and overexpressed in most inflammatory states, we decided to assess TNF- $\alpha$ and IL- 6 protein secretion in LPS-stimulated $\mathrm{M} \varphi$ pretreated with PEG-LNP(Cal) and targeted PEG-LNP(Cal) by ELISA. ${ }^{41}$ Both PEG-LNP(Cal) and targeted PEG-LNP(Cal) significantly suppressed TNF- $\alpha$ secretion in a dose-dependent manner as compared to treatment with free calcitriol in LPS-stimulated $\mathrm{M} \varphi$ (data not shown). Similarly, IL-6 secretion was slightly reduced, albeit not significantly, after treatment with both PEG-LNP(Cal) and targeted PEG-LNP(Cal) (Figure $3 \mathrm{G}$ and $\mathrm{H}$ ). In addition, we further evaluated the effect of CD163-targeted PEGLNP(Cal) on the surface marker expression of HLA-DR and CD80 in $\mathrm{DID}^{+} \mathrm{M} \varphi$. We observed that the expression of surface marker HLA-DR markedly declined in LPS-induced $\mathrm{DID}^{+} \mathrm{M} \varphi$ pretreated with $100 \mathrm{nM}$ of PEG-LNP(Cal)ahCD163. Additionally, CD80 expression decreased in proportion to increasing calcitriol concentrations in $\mathrm{DID}^{+}$ 

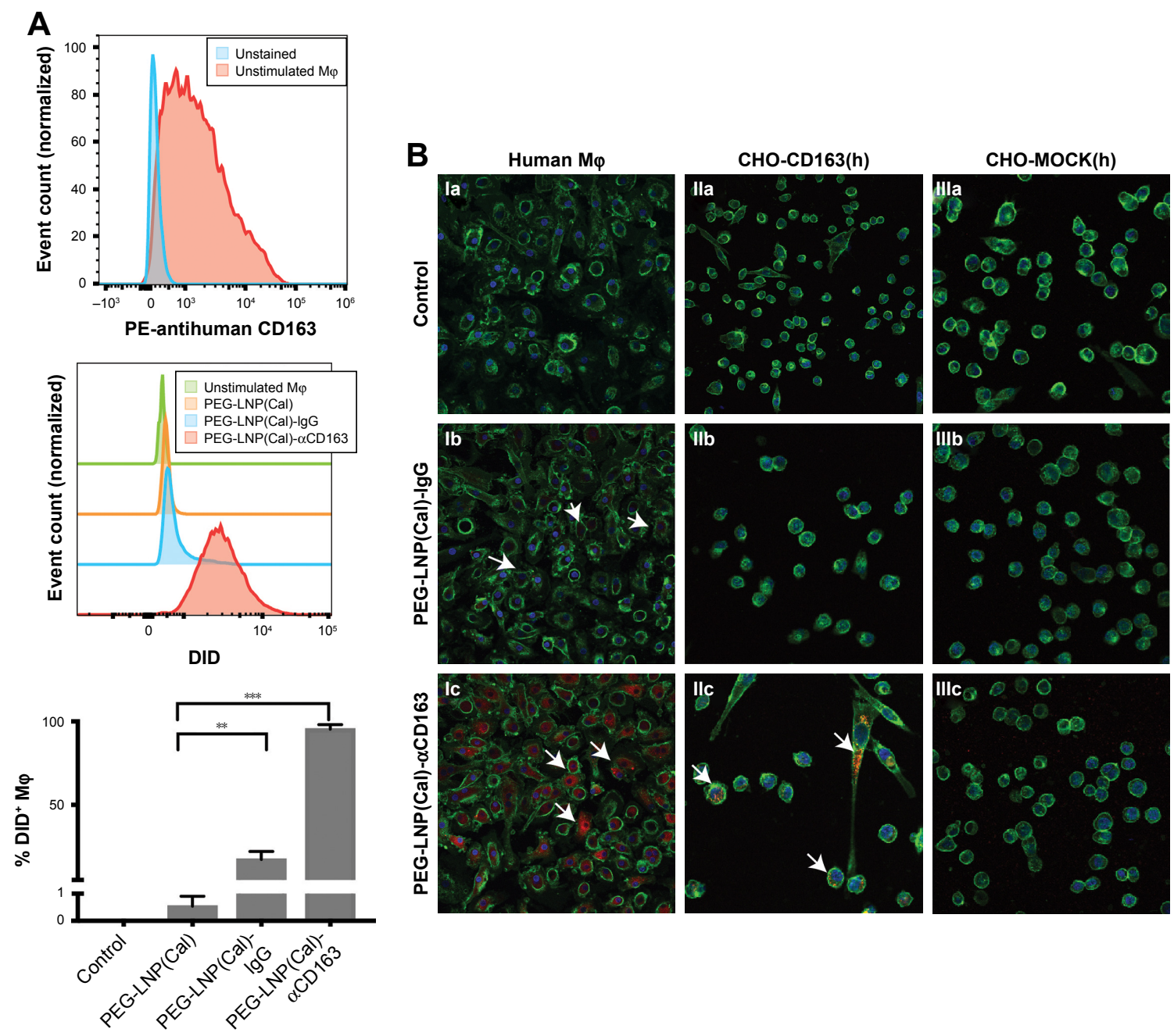

Figure 2 Uptake of DID near-infrared non-targeted and targeted PEG-LNP(Cal) by M $\varphi$ and CHO-CDI63-transfected cells. (A) Specific uptake of non-targeted, IgG, and

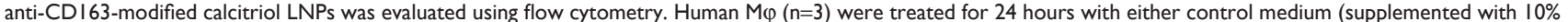
CS-FBS), 100 nM DID PEG-LNP(Cal), 100 nM DID PEG-LNP(Cal)-IgG, or 100 nM DID PEG-LNP(Cal)- $\alpha C D I 63$. Cells were stained with Live/Dead and PE-antihuman CDI63. Histograms were generated to evaluate particle uptake. First panel: histograms of unstained M $\varphi$ (blue) and control (non-stimulated) $M \varphi$ (red); second (middle): histograms of I) non-stimulated M $\varphi$, 2) PEG-LNP(Cal), 3) PEG-LNP(Cal)-lgG, 4) PEG-LNP(Cal)- $\alpha C D I 63$; third (last): graph shows the uptake of non-targeted, lgG-, and anti-CDI63modified calcitriol LNPs by \% DID+ M $\varphi$. One-way ANOVA analysis and Dunnett's multiple comparisons test were used to compare the means of the IgG-targeted and CDI63-targeted calcitriol LNPs with the mean of the non-targeted calcitriol LNPs. **Non-targeted PEG-LNP(Cal) vs PEG-LNP(Cal)-lgG. ***Non-targeted PEG-LNP(Cal) vs PEG-LNP(Cal)- $\alpha$ CDI63. (For gating strategy, see Figure SIA.) (B) Specific uptake of DID fluorescent-targeted LNPs was further visualized by confocal microscopy for $\mathrm{M} \varphi$ (la-lc), human CDI63-transfected CHO cells (Illa-llc), and control CHO-MOCK(h) (Illa-Illc). Cells were settled on chambered coverslips and stimulated for 24 hours with either control medium, 25 nM DID PEG-LNP(Cal)-IgG, or 25 nM DID PEG-LNP(Cal)- $\alpha$ CD I63. LNP tracer DID together with calcitriol in LNPs (red). Cell membranes were stained with wheat germ agglutinin Alexa Flour 488 (green) and DAPI (blue) was used for counterstaining the cell nuclei. All images were visualized using a Fluoview FVI 000 - laser I: $405 \mathrm{~nm}$ (transmissivity 500\%), laser 2: $488 \mathrm{~nm}$ (transmissivity 256\%), laser 3: $635 \mathrm{~nm}$ (transmissivity 490\%). White arrows indicate the uptake of DID PEGLNP(Cal)-lgG and DID-PEG-LNP(Cal)- $\alpha$ CDI63.

Abbreviations: M $\varphi$, macrophages; LNPs, lipid nanoparticles; LNP(Cal), conventional calcitriol LNPs; PEG, polyethylene glycol; PEG-LNP(Cal), calcitriol PEGylated lipid nanoparticles; CS, charcoal stripped.

$\mathrm{M} \varphi$, however, but not compared to untreated LPS-induced $\mathrm{M} \varphi$ (Figure 3I and J).

\section{In vivo biodistribution and pharmacokinetic study of CDI63- targeted calcitriol LNPs vs non-targeted calcitriol LNPs in mice}

In order to address specific delivery and evaluate the biodistribution of the LNP system in healthy SWISS mice in vivo, DID PEG-LNP(Cal) were modified with $\alpha \mathrm{mCD} 163$ or the corresponding control rat IgG. Live animals were imaged at 15, 45, 90, 150, and 210 minutes post-IV administration using a Xenogen IVIS $^{\circledR}$ in vivo imaging system. Both PEG-LNP(Cal)-IgG and PEG-LNP(Cal)- $\alpha$ mCD163 showed increased accumulation in the upper abdominal part of the animals as compared to PEG-LNP(Cal), which seemed to circulate in the blood for a longer period of time (Figure 4A). An in vivo pharmacodynamic study was 
performed to assess the clearance of PEG-LNP(Cal) and IgG- and anti-CD163 mAB-modified PEG-LNP(Cal). Nineweek-old C57BL/6JRj mice $(n=4)$ were injected IV with LNP formulations $(0.1 \mathrm{mg} / \mathrm{kg})$, and $20 \mu \mathrm{L}$ blood samples were collected at seven different time points $(T=1$ and 30 minutes, and 1, 2, 4, 6, and 24 hours). The LNP DID fluorescence intensity was measured using a Xenogen in vivo imaging system (Figure 4B). Due to dilution of the total encapsulated calcitriol concentration in LNP formulations, which likely influenced the total DID fluorescence and particle concentration, a normalization factor was added to all total radiant efficiencies. We observed rapid clearance of PEG-LNP(Cal)-IgG and PEG-LNP(Cal)- $\alpha$ mCD163 in the first 30 minutes and up to 2 hours postinjection, compared to the prolonged circulation of PEG-LNP(Cal). We also observed a significant difference in the clearance of targeted
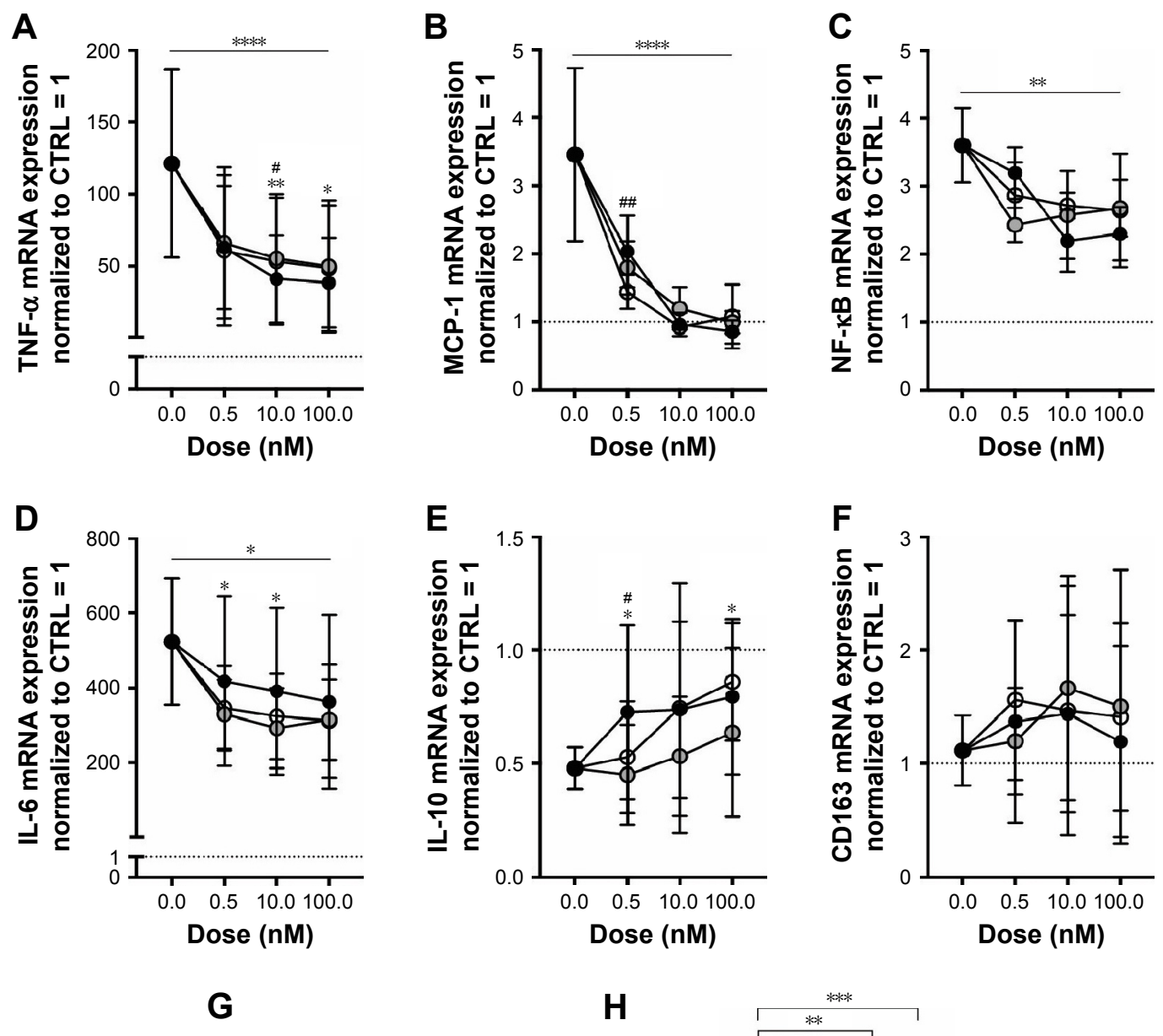

H
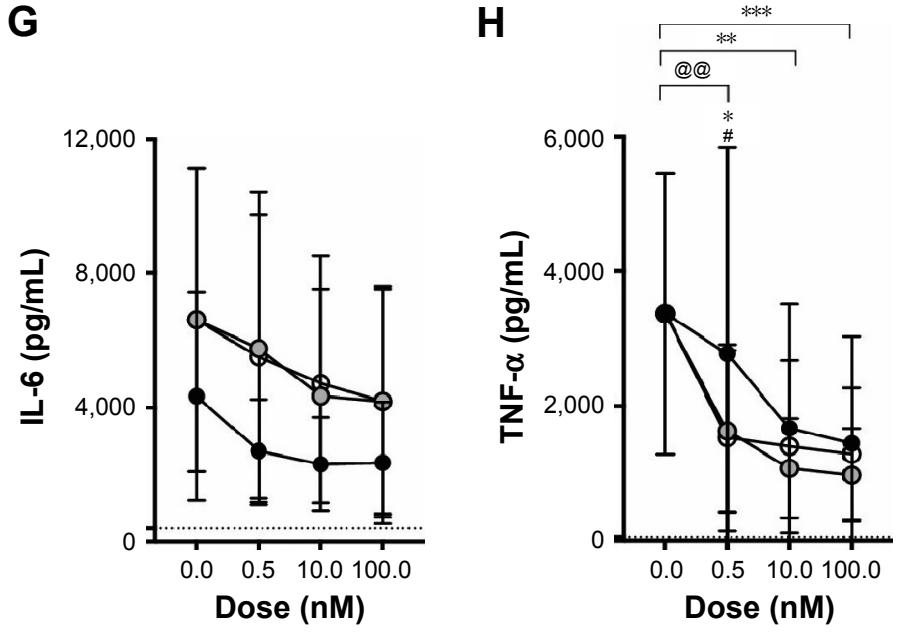

๑ PEG-LNP(Cal) -O- PEG-LNP(Cal)-lgG

PEG-LNP(Cal)- $\alpha$ hCD163 

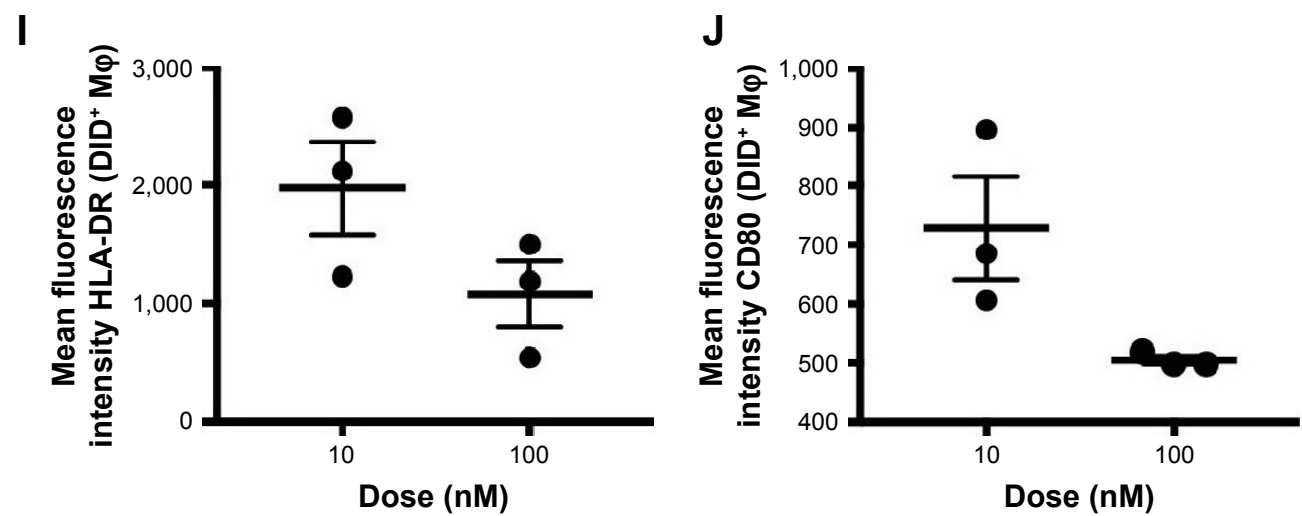

PEG-LNP(Cal)- $\alpha$ CD163

Figure 3 mRNA gene expression analyses of selected target genes, protein analyses of IL-6 and TNF- $\alpha$, and analysis of surface marker expression of HLA-DR and CD80 to investigate the effects of non-targeted and targeted PEG-LNP(Cal) in LPS-induced human M $\varphi$. (A-H) Human M $\varphi$ (I $\times 10^{6}$ cells/well) from buffy coats ( $\left.n=3\right)$ were pretreated with different doses $(0.5,10$, and $100 \mathrm{nM}$ ) of either PEG-LNP(Cal), PEG-LNP(Cal)-lgG(h), or PEG-LNP(Cal)- $\alpha$ hCDI63 for 24 hours following LPS challenge ( $\mu \mathrm{L} / \mathrm{mL})$ for 4 hours. The second derivative max method was used to calculate the relative mRNA concentration of each sample. Target gene expression levels (NF- $\kappa B$, TNF- $\alpha$, MCP-I, IL-6, IL-I0, and CDI63) were normalized to the stable housekeeping gene GAPDH expression level, and the resulting mRNA ratios were normalized to untreated control M $\varphi$ and given the value I (dotted horizontal line). Two-way ANOVA along with Tukey's multiple comparisons test was performed on all targets to investigate the difference between LNP types per dose and the specific dose-dependent response per LNP type. $* P \leq 0.05, * * P \leq 0.01$, $* * * P \leq 0.00 \mathrm{I}$, and $* * * * P \leq 0.000 \mathrm{I}$. Asterisks over the horizontal line indicate dose-dependent significance. (A) ${ }^{*} 10 \mathrm{nM}$ PEG-LNP(Cal) vs $10 \mathrm{nM}$ PEG-LNP(Cal)- $\alpha \mathrm{hCD} \mid 63$, * and **PEG-LNP(Cal)-lgG(h) vs PEG-LNP(Cal)- $\alpha \mathrm{hCDI}$ 63. (B) \#PEGLNP(Cal) vs PEG-LNP(Cal)- $\alpha$ hCDI63. (C) **The horizontal line above shows dose-dependent significance for non-targeted and targeted PEG-LNP(Cal). (D) *The horizontal line above illustrates significant dose-dependent response for PEG-LNP(Cal) and PEG-LNP(Cal)-lgG(h). *For both 0.5 and I0 nM PEG-LNP(Cal)-lgG(h) vs 0.5 and I0 nM PEGLNP(Cal)- $\alpha$ hCDI63. (E) ${ }^{*} 0.5 \mathrm{nM}$ PEG-LNP(Cal) vs $0.5 \mathrm{nM}$ PEG-LNP(Cal)- $\alpha$ hCDI63, *0.5 and $100 \mathrm{nM}$ PEG-LNP(Cal)-lgG(h) vs 0.5 and I00 nM PEG-LNP(Cal)- $\alpha$ hCDI 63 . $(\mathbf{G}, \mathbf{H})$ Cell culture supernatant was collected from $M \varphi(n=3)$. Protein concentration of $(\mathbf{G})$ IL-6 * (outlier removed from IL-6 ELISA) and $(\mathbf{H})$ TNF- $\alpha$ protein level $(\mathrm{pg} / \mathrm{mL})$ was measured using a commercial human IL- 6 and TNF- $\alpha$ kit. Dotted horizontal line indicates the protein level detected in control M $\varphi$. Two-way ANOVA with Tukey's multiple comparisons test was performed. ***Statistically significant difference for all $100 \mathrm{nM}$ LNP types. **For all I0 nM LNP types. @@For $0.5 \mathrm{nM}$ PEG-LNP(Cal) and $0.5 \mathrm{nM}$ PEG-LNP(Cal)-lgG(h). ${ }^{\#} 0.5 \mathrm{nM}$ PEG-LNP(Cal) vs $0.5 \mathrm{nM}$ PEG-LNP(Cal)- $\alpha$ hCDI63. *0.5 nM PEG-LNP(Cal)-lgG(h) vs $0.5 \mathrm{nM}$ PEG-LNP(Cal)- $\alpha$ hCDI63. (I, J) MFI of surface markers HLA-DR and CD80 on DID+ LPS-induced M $\varphi$ pretreated with 10 and $100 \mathrm{nM}$ PEG-LNP(Cal)- $\alpha$ hCDI63. Overall MFI of surface markers on live LPS-induced M $\varphi$ population; mean MFI HLA-DR: 1978 and mean MFI CD80: 446.

Abbreviations: M $\varphi$, macrophages; LNPs, lipid nanoparticles; PEG, polyethylene glycol; PEG-LNP(Cal), calcitriol PEGylated lipid nanoparticles; LPS, lipopolysaccharide; MFI, median fluorescence intensity; TNF- $\alpha$, tumor necrosis factor-alpha; MCP-I, monocyte chemoattractant protein; NF, nuclear factor; IL, interleukin.

PEG-LNP(Cal) compared to non-targeted PEG-LNP(Cal) over time from 4 to 6 hours (Figure 4B). PEG-coated particles are known as long circulating lipid particles and have longer half-lives compared to conventional or targeted LNPs. ${ }^{42}$ Blood samples collected 24 hours post-administration also confirmed the total clearance of non-targeted PEG-LNP(Cal), PEG-LNP(Cal)-IgG, and PEG-LNP(Cal)$\alpha \mathrm{mCD} 163$ in blood, comparable to the control PBS mice group (not shown). At 25 hours post-LNP administration, ex vivo imaging of the organs confirmed the accumulation of PEG-LNP(Cal) only in the liver, in contrast to the accumulation of PEG-LNP(Cal)- $\alpha \mathrm{mCD} 163$ in the liver and spleen. Moreover, we observed a similar accumulation of PEG-LNP(Cal)-IgG in the liver, spleen and (modestly) kidney (Figure 4C-D).

\section{Discussion}

To the best of our knowledge, this is the first study describing the targeting of calcitriol specifically to $M \varphi$ using antibody-modified LNPs. Monocytes and $\mathrm{M} \varphi$ are key players in several inflammatory disorders and cancers, and specific targeting of these cells has been shown to result in increased drug efficacy with fewer side effects. ${ }^{35,43,44}$ In the case of vitamin $\mathrm{D}_{3}$ the risk of hypercalcemia hinders the use of high dose systemic treatment. Recent attempts have been made to overcome this involving the encapsulation of calcitriol in nanoemulsions, liposomes, and PLGA nanoparticles. ${ }^{2,3,31,45}$ Although such nanoparticles accumulate at the sites of inflammation or in tumor tissue due to the enhanced permeability and retention effect, ${ }^{46,47}$ further improvement of the therapeutic index may be obtained by specific targeting of the inflammatory cells, in essence reducing the adverse effects of toxic therapeutic agents caused by systemic uptake. We used the M $\varphi$ specific receptor CD163 as a target for antibodymodified LNPs. CD163 is an obvious target due to its high expression on $\mathrm{M} \varphi \mathrm{s}$ in general and especially at sites of inflammation and cancer, ${ }^{48,49}$ as well as its endocytic nature, which results in the daily removal of gram levels of hemoglobin from the circulation. ${ }^{44,50} \mathrm{We}$ successfully produced stable PEGylated calcitriol LNPs and were able to conjugate human and mouse mABs with a strong affinity for CD163 to the particles, as demonstrated by SPR analysis. Single cell analysis showed an increased uptake of PEG-LNP(Cal)- $\alpha$ CD163 by $\mathrm{M} \varphi$ compared to the internalization of PEG-LNP(Cal) and 


\section{A}

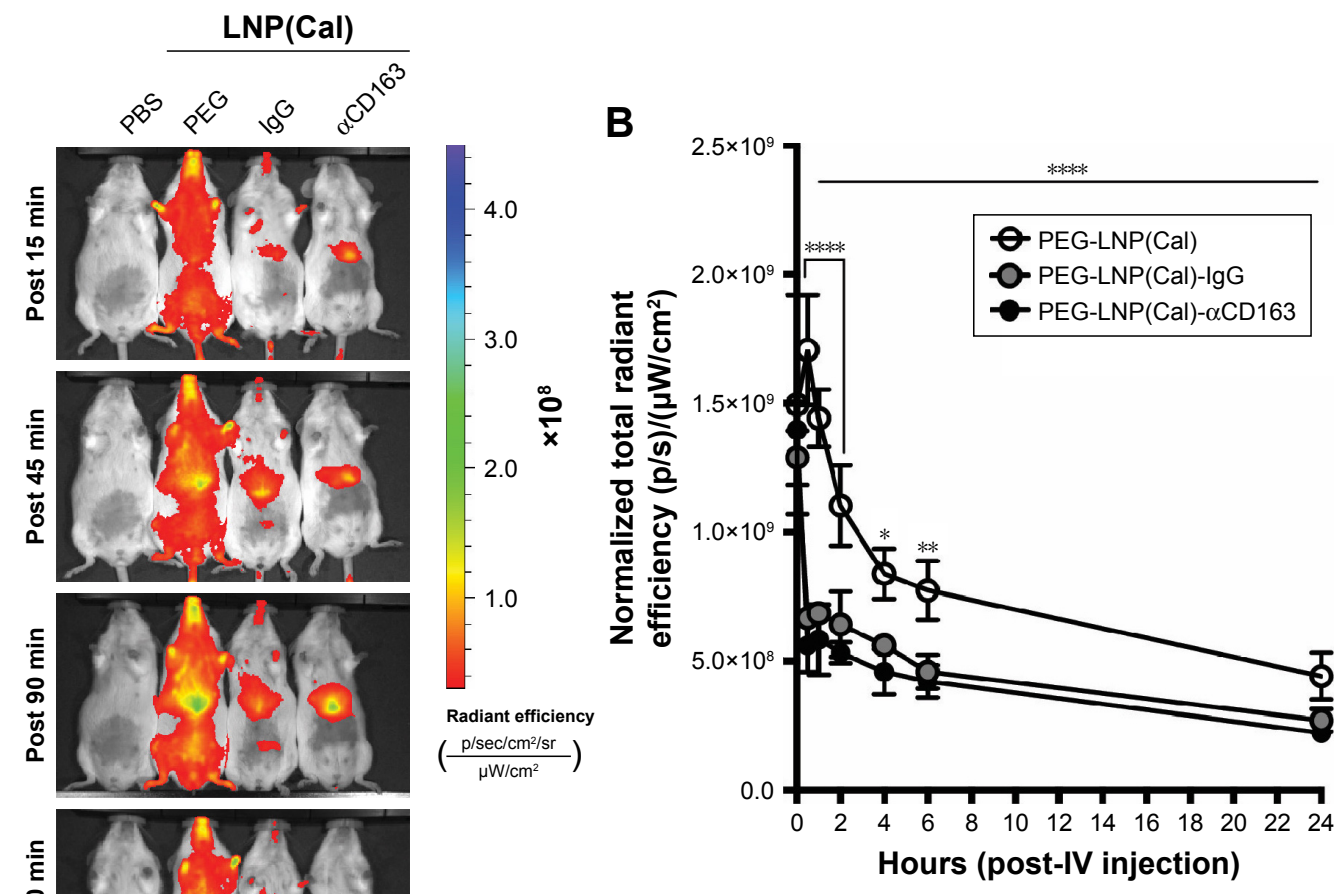

D

D LNP(Cal)
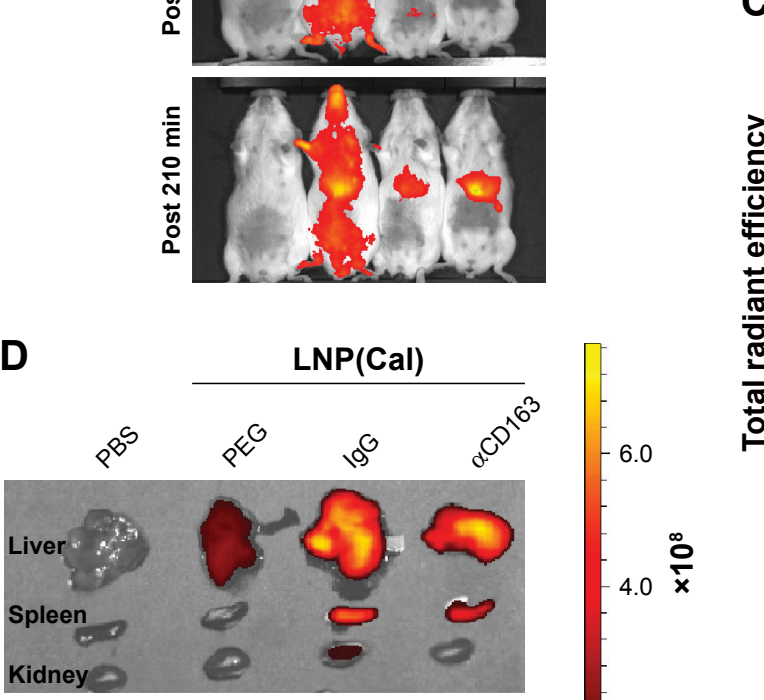

C
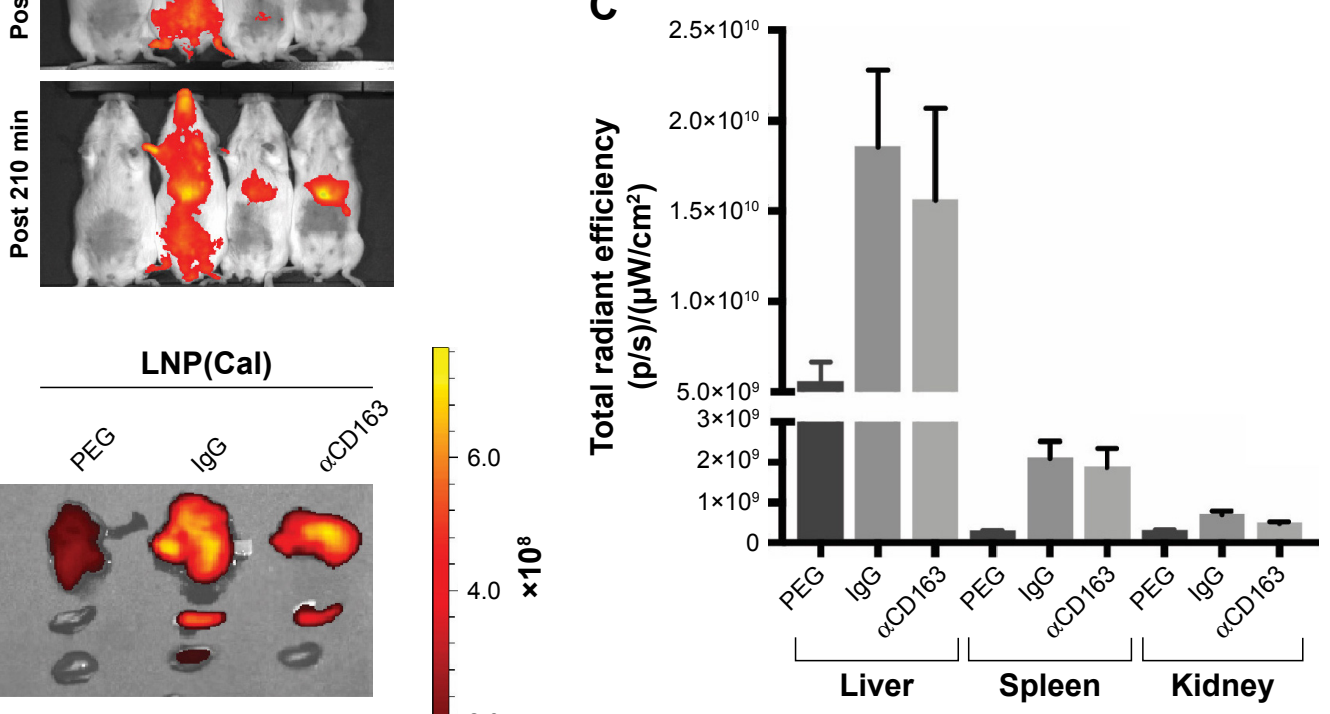

2.0

Figure 4 In vivo time-resolved biodistribution, pharmacokinetics, and ex vivo accumulation of near-infrared non-targeted and targeted PEG-LNP(Cal) in mice. (A) SWISS mice $(\mathrm{n}=\mathrm{I})$ were injected with either $400 \mu \mathrm{L}$ saline water, $400 \mu \mathrm{L}$ PEG-LNP(Cal) $\left(0.1 \mathrm{mg} / \mathrm{kg} 1.25(\mathrm{OH})_{2} \mathrm{D}_{3}\right), 400 \mu \mathrm{L}$ PEG-LNP(Cal)-IgG(m), or PEG-LNP(Cal)- $\alpha \mathrm{mCDI} 63$ $\left(0.05 \mathrm{mg} / \mathrm{kg} \mathrm{I.25}(\mathrm{OH})_{2} \mathrm{D}_{3}\right)$. LNP biodistribution was measured at I5, 45, 90, 150, and 210 minutes post-insertion using a Xenogen IVIS ${ }^{\oplus}$ in vivo imaging system at Ex/Em 644/665. Living Image Software was used to apply spectral unmixing on all images to subtract background autofluorescence. The rainbow color scale on the in vivo images represents signal intensity, with purple being the most intense and red being the least intense. (B) $C 57 \mathrm{BL} / 6) \mathrm{Rj}$ mice $(\mathrm{n}=4)$ were injected intravenously with either saline water, PEG-LNP(Cal), PEG-LNP(Cal)-lgG(m), or PEG-LNP(Cal)- $\alpha \mathrm{mCDI} 63\left(0.1 \mathrm{mg} / \mathrm{kg} 1.25(\mathrm{OH})_{2} \mathrm{D}_{3}\right.$ for all) at $\mathrm{T}=0$. Blood samples were collected from the sublingual vein I minute postinjection, and $20 \mu \mathrm{L}$ blood samples were collected in capillary tubes from the tail vein at the following time points: T=30 minutes, and I, 2, 4, 6, and 24 hours. Particle DID fluorescence intensity was measured in all blood samples with a Xenogen IVIS ${ }^{\circledast}$ in vivo imaging system at Ex/Em 644/665 and plotted as normalized total radiant efficiency. For statistical analysis, two-way ANOVA with Tukey's multiple comparisons test was performed. $* * * * P \leq 0.000 \mathrm{I}$ over the horizontal line shows overall statistically significant difference between clearance of DID PEG-LNP(Cal) and DID PEG-LNP(Cal)-lgG(m) and clearance of DID PEG-LNP(Cal) and PEG-LNP(Cal)$\alpha \mathrm{mCDI}$ 63. ****30 minutes-2 hours (DID PEG-LNP(Cal) vs DID PEG-LNP(Cal)-lgG(m)) and (DID PEG-LNP(Cal) vs PEG-LNP(Cal)- $\alpha \mathrm{mCDI}$ (63). *DID PEG-LNP(Cal) vs DID PEG-LNP(Cal)-lgG(m) and DID PEG-LNP(Cal) vs PEG-LNP(Cal)- $\alpha \mathrm{mCDI} 63$ at 4 hours. **DID PEG-LNP(Cal) vs DID PEG-LNP(Cal)-lgG(m) and DID PEG-LNP(Cal) vs PEG-LNP(Cal)- $\alpha \mathrm{mCDI} 63$ at 6 hours. (C, D) After 25 hours, the animals were sacrificed, and the organs (liver, spleen, and kidney) were harvested for ex vivo imaging. A pseudo-color scale on the ex vivo image represents the light intensity (red is least intense while yellow is most intense), and the total radiant efficiency of the organs (liver, spleen, kidney $(\mathrm{n}=4))$ is plotted to visualize calcitriol LNP accumulation.

Abbreviations: LNPs, lipid nanoparticles; PEG, polyethylene glycol; PEG-LNP(Cal), calcitriol PEGylated lipid nanoparticles; IV, intravenous. 
PEG-LNP(Cal)-IgG. Confocal microscopy confirmed that CD163-targeted calcitriol particles were effectively taken up by CD163-expressing CHO cells, whereas control IgGmodified particles were not. In $\mathrm{M} \varphi$, we observed increased uptake of anti-CD163-modified calcitriol LNPs and a modest uptake of IgG-modified calcitriol LNPs. The latter result is probably due to the nonspecific uptake of $\operatorname{IgG}$ particles by Fc receptors. In an in vitro system of LPS stimulation of $\mathrm{M} \varphi$, anti-CD163-modified, IgG-modified, and non-targeted calcitriol LNPs all showed a strong inhibitory effect on the mRNA gene expression of pro-inflammatory markers (TNF- $\alpha$, NF- $\kappa$ B, MCP-1, and to a lesser extent, IL-6), but a stimulatory effect on anti-inflammatory IL-10. However, it has been reported that calcitriol induces MCP-1 expression in dendritic cells in multiple sclerosis patients ${ }^{51}$ but suppresses LPS-induced MCP-1 in the human monocytic cell line THP- $1 .{ }^{52}$ The in vitro system, not reflecting the in vivo circulation, precludes the possibility for demonstrating a superior effect of receptor-targeted particles vs unmodified particles, as both types of LNPs will be taken up by М $\varphi$. Furthermore, even though we observed specific and significant increased internalization of CD163-targeted calcitriol LNPs by M $\varphi$, this was not fully reflected in the specific inhibitory effect of calcitriol on pro-inflammatory cytokine gene expression, as we observed an inhibitory effect on both IgG- and CD163-targeted and non-targeted LNPs. This may be due to the (short) 24-hour incubation period in vitro, as intracellular drug release and subsequent effects may be more efficient and effective after a longer incubation period (eg, 48-72 hours) with non-targeted and mAB-modified (IgG and CD163) calcitriol LNPs in vitro. Investigating the rate of drug (calcitriol) release in this specific drug-delivery system may also improve our understanding with regard to the lack of increased anti-inflammatory effects of CD163targeted LNPs. Interestingly, we observed a dose-dependent decrease in the surface marker expression of HLA-DR and the co-stimulatory surface molecule CD80 exclusively in $\mathrm{DID}^{+}$LPS-induced $\mathrm{M} \varphi$ pretreated with PEG-LNP(Cal)$\alpha \mathrm{CD} 163$. However, we observed a lower CD80 expression in untreated LPS-induced M $\varphi$. This may be due to the fact that the LPS-induced $\mathrm{M} \varphi$ mean fluorescence intensity (MFI) reflects the expression of $\mathrm{CD} 80$ in the total $\mathrm{M} \varphi$ population, whereas the surface expression of CD80 on PEG-LNP(Cal)$\alpha C D 163$-treated $\mathrm{M} \varphi$ reflects the MFI of $\mathrm{DID}^{+} \mathrm{M} \varphi$. This problem could be avoided by treating $\mathrm{M} \varphi$ with empty targeted particles. In general, these data support the well-described anti-inflammatory and immunoregulatory role of calcitriol in myeloid cells. ${ }^{11,53-57} \mathrm{We}$ then investigated the biodistribution and tissue accumulation of DID fluorescent non-targeted and mAB-modified (IgG and CD163) LNPs in vivo in mice. The increased circulation of PEG-LNPs in the blood flow could be due to their improved stability as well as the half-life extension of these LNPs, compared to conventional LNPs, which undergo rapid clearance due to destabilization and opsonization of plasma components. ${ }^{58,59}$ However, targeting LNPs toward specific monocyte/ $\mathrm{M} \varphi$ receptors can provide effective uptake and thereby reduce uptake by other $\mathrm{M} \varphi$ subsets. ${ }^{35}$ We observed an increased accumulation of both PEGLNP(Cal)-IgG and PEG-LNP(Cal)- $\alpha$ CD163 in the upper abdomen as compared to PEG-LNP(Cal). Due to the route of injection, mAB-modified calcitriol LNPs are most likely captured by hepatic $\mathrm{M \varphi}$ (Kupffer cells) in the liver and by splenic red-pulp $\mathrm{M} \varphi$, as these cells are in direct contact with the bloodstream. Nevertheless, the uptake of IgG-targeted calcitriol LNPs, most likely by the Fc receptor, should also not be underestimated because these particles are also taken up by the majority of $\mathrm{M} \varphi$ in the liver and spleen. Interestingly, particle characteristics and the route of administration play a significant role in particle uptake and tissue-specific accumulation. IgG-modified LNP delivery systems administered subcutaneously have been shown to be useful for the targeting of, for example, regional lymph nodes, ${ }^{60}$ and orally administered Fc receptor-targeted nanoparticles have been shown to enter systemic circulation through transepithelial transport. ${ }^{61}$ In conclusion, our study shows for the first time the targeting of calcitriol specifically to $M \varphi$. In summary, we demonstrate the uptake and effect of PEGylated and AB-modified calcitriol LNPs on human $M \varphi$ in vitro and bioavailability in vivo. We were able to deliver the bioactive metabolite to M $\varphi$. The targeting of CD163 for the specific delivery of calcitriol may be a useful approach for the treatment of chronic inflammatory diseases while potentially avoiding adverse side effects.

\section{Acknowledgments}

We acknowledge laboratory technicians Christina Strande Søndeskov and Helle Hausser Ryom, and animal caretaker Kristoffer Augustensen for their excellent technical assistance. Danish Council for Strategic Research (TRAIN 10-092797), Vilhelm Bangs Fund, Lily Benthine Lunds Fund of 1.6.1978, and Laegefonden supported the studies.

\section{Author contributions}

All authors contributed toward data analysis, drafting and revising the paper, gave final approval of the version to 
be published and agree to be accountable for all aspects of the work.

\section{Disclosure}

Dr Jonas H Graversen reports assistance from Affinicon during the conduct of the study. The authors report no other conflicts of interest in this work.

\section{References}

1. Immordino ML, Dosio F, Cattel L. Stealth liposomes: review of the basic science, rationale, and clinical applications, existing and potential. Int J Nanomedicine. 2006;1(3):297-315.

2. Maradana MR, Yekollu SK, Zeng B, et al. Immunomodulatory liposomes targeting liver macrophages arrest progression of nonalcoholic steatohepatitis. Metabolism. 2018;78:80-94. doi:10.1016/j.metabol.2017.09.002

3. El-Sherbiny M, Eldosoky M, El-Shafey M, et al. Vitamin D nanoemulsion enhances hepatoprotective effect of conventional vitamin D in rats fed with a high-fat diet. Chem Biol Interact. 2018;288:65-75. doi:10.1016/j.cbi.2018.04.010

4. Tacke F. Targeting hepatic macrophages to treat liver diseases. J Hepatol. 2017;66(6):1300-1312.

5. Svendsen P, Graversen JH, Etzerodt A, et al. Antibody-directed glucocorticoid targeting to CD163 in M2-type macrophages attenuates fructose-induced liver inflammatory changes. Mol Ther Methods Clin Dev. 2017;4:50-61.

6. Nardin A, Lefebvre ML, Labroquere K, Faure O, Abastado JP. Liposomal muramyl tripeptide phosphatidylethanolamine: targeting and activating macrophages for adjuvant treatment of osteosarcoma. Curr Cancer Drug Targets. 2006;6(2):123-133.

7. Neve A, Corrado A, Cantatore FP. Immunomodulatory effects of vitamin $\mathrm{D}$ in peripheral blood monocyte-derived macrophages from patients with rheumatoid arthritis. Clin Exp Med. 2014;14(3):275-283.

8. Tacke F, Zimmermann HW. Macrophage heterogeneity in liver injury and fibrosis. J Hepatol. 2014;60(5):1090-1096.

9. Schmidt-Arras D, Rose-John S. IL-6 pathway in the liver: from physiopathology to therapy. J Hepatol. 2016;64(6):1403-1415.

10. Beilfuss J, Berg V, Sneve M, Jorde R, Kamycheva E. Effects of a 1-year supplementation with cholecalciferol on interleukin-6, tumor necrosis factor-alpha and insulin resistance in overweight and obese subjects. Cytokine. 2012;60(3):870-874. doi:10.1016/j.cyto.2012.07.032

11. Giulietti A, van Etten E, Overbergh L, Stoffels K, Bouillon R, Mathieu C. Monocytes from type 2 diabetic patients have a pro-inflammatory profile. 1,25-dihydroxyvitamin D(3) works as anti-inflammatory. Diabetes Res Clin Pract. 2007;77(1):47-57. doi:10.1016/j.diabres.2006.10.007

12. Beyer M, Mallmann MR, Xue J, et al. High-resolution transcriptome of human macrophages. PLoS One. 2012;7(9):e45466. doi:10.1371/ journal.pone.0045466

13. Mills CD, Thomas AC, Lenz LL, Munder M. Macrophage: SHIP of immunity. Front Immunol. 2014;5:620. doi:10.3389/fimmu.2014.00620

14. Etzerodt A, Moestrup SK. CD163 and inflammation: biological, diagnostic, and therapeutic aspects. Antioxid Redox Signal. 2013;18(17):2352-2363. doi:10.1089/ars.2012.4834

15. Etzerodt A, Kjolby M, Nielsen MJ, Maniecki M, Svendsen P, Moestrup SK. Plasma clearance of hemoglobin and haptoglobin in mice and effect of CD163 gene targeting disruption. Antioxid Redox Signal. 2013; 18(17):2254-2263. doi:10.1089/ars.2012.4605

16. Omatsu M, Kunimura T, Mikogami T, et al. Difference in distribution profiles between CD163+ tumor-associated macrophages and S100+ dendritic cells in thymic epithelial tumors. Diagn Pathol. 2014;9:215. doi:10.1186/s13000-014-0215-7

17. Di Rosa M, Malaguarnera G, De Gregorio C, Palumbo M, Nunnari G, Malaguarnera L. Immuno-modulatory effects of vitamin D3 in human monocyte and macrophages. Cell Immunol. 2012;280(1):36-43. doi:10.1016/j.cellimm.2012.10.009
18. Sylvia Christakos PD, Verstuyf A, Verlinden L, Carmeliet G. Vitamin D: metabolism, molecular mechanism of action and pleiotropic effects. Physiol Rev. 2016;96(1):365-408.

19. Vanherwegen AS, Gysemans C, Mathieu C. Vitamin D endocrinology on the cross-road between immunity and metabolism. Mol Cell Endocrinol. 2017;453:52-67. doi:10.1016/j.mce.2017.04.018

20. Hewison M, Freeman L, Hughes SV, et al. Differential regulation of vitamin $\mathrm{D}$ receptor and its ligand in human monocyte-derived dendritic cells. J Immunol. 2003;170(11):5382-5390.

21. Veldman CM, Cantorna MT, DeLuca HF. Expression of 1,25-dihydroxyvitamin D(3) receptor in the immune system. Arch Biochem Biophys. 2000;374(2):334-338. doi:10.1006/abbi.1999.1605

22. Chen S, Sims GP, Chen XX, Gu YY, Chen S, Lipsky PE. Modulatory effects of 1,25-dihydroxyvitamin D3 on human B cell differentiation. J Immunol. 2007;179(3):1634-1647.

23. Jeffery LE, Wood AM, Qureshi OS, et al. Availability of 25-hydroxyvitamin $\mathrm{D}(3)$ to APCs controls the balance between regulatory and inflammatory T cell responses. J Immunol. 2012;189(11):5155-5164. doi:10.4049/jimmunol.1200786

24. Garbossa SG, Folli F. Vitamin D, sub-inflammation and insulin resistance. A window on a potential role for the interaction between bone and glucose metabolism. Rev Endocr Metab Disord. 2017;18:243-258. doi:10.1007/s11154-017-9423-2

25. Bessler H, Djaldetti M. 1alpha,25-dihydroxyvitamin D3 modulates the interaction between immune and colon cancer cells. Biomed Pharmacother. 2012;66(6):428-432. doi:10.1016/j.biopha.2012.06.005

26. Smith DC, Johnson CS, Freeman CC, Muindi J, Wilson JW, Trump DL. A Phase I trial of calcitriol (1,25-dihydroxycholecalciferol) in patients with advanced malignancy. Clin Cancer Res. 1999;5(6): 1339-1345.

27. Deeb KK, Trump DL, Johnson CS. Vitamin D signalling pathways in cancer: potential for anticancer therapeutics. Nat Rev Cancer. 2007;7(9):684-700. doi:10.1038/nrc2196

28. Chen Y, Liu W, Sun T, et al. 1,25-dihydroxyvitamin D promotes negative feedback regulation of TLR signaling via targeting microRNA155-SOCS1 in macrophages. J Immunol. 2013;190(7):3687-3695. doi:10.4049/jimmunol.1203273

29. Chen Y, Zhang J, Ge X, Du J, Deb DK, Li YC. Vitamin D receptor inhibits nuclear factor kappaB activation by interacting with IkappaB kinase beta protein. J Biol Chem. 2013;288(27):19450-19458. doi:10.1074/jbc.M113.467670

30. Han X, Li L, Yang J, King G, Xiao Z, Quarles LD. Counter-regulatory paracrine actions of FGF-23 and 1,25(OH)2 D in macrophages. FEBS Lett. 2016;590(1):53-67. doi:10.1002/1873-3468.12040

31. Liu C, Shaurova T, Shoemaker S, Petkovich M, Hershberger PA, Wu Y. Tumor-targeted nanoparticles deliver a vitamin D-based drug payload for the treatment of EGFR tyrosine kinase inhibitor-resistant lung cancer. Mol Pharm. 2018;5(8):3216-3226.

32. Zhigaltsev IV, Belliveau N, Hafez I, et al. Bottom-up design and synthesis of limit size lipid nanoparticle systems with aqueous and triglyceride cores using millisecond microfluidic mixing. Langmuir. 2012;28(7):3633-3640.

33. Ulbrich W, Lamprecht A. Targeted drug-delivery approaches by nanoparticulate carriers in the therapy of inflammatory diseases. $J R$ Soc Interface. 2010;7(Suppl 1):S55-S66.

34. Alaarg A, Jordan NY, Verhoef JJ, Metselaar JM, Storm G, Kok RJ. Docosahexaenoic acid liposomes for targeting chronic inflammatory diseases and cancer: an in vitro assessment. Int $J$ Nanomedicine. 2016;11:5027-5040.

35. Etzerodt A, Maniecki MB, Graversen JH, Moller HJ, Torchilin VP, Moestrup SK. Efficient intracellular drug-targeting of macrophages using stealth liposomes directed to the hemoglobin scavenger receptor CD163. J Control Release. 2012;160(1):72-80.

36. Madsen M, Moller HJ, Nielsen MJ, et al. Molecular characterization of the haptoglobin.hemoglobin receptor CD163. Ligand binding properties of the scavenger receptor cysteine-rich domain region. J Biol Chem. 2004;279(49):51561-51567. 
37. Torchilin VP, Levchenko TS, Lukyanov AN, et al. p-Nitrophenylcarbonyl-PEG-PE-liposomes: fast and simple attachment of speciфc ligands, including monoclonal antibodies, to distal ends of PEG chains via p-nitrophenylcarbonyl groups. Biochim Biophys Acta. 2001;1511(2001):397-411.

38. Marques-Gallego P, de Kroon AI. Ligation strategies for targeting liposomal nanocarriers. Biomed Res Int. 2014;2014:129458.

39. Vandooren J, Born B, Solomonov I, et al. Circular trimers of gelatinase B/matrix metalloproteinase-9 constitute a distinct population of functional enzyme molecules differentially regulated by tissue inhibitor of metalloproteinases-1. Biochem J. 2015;465(2):259-270.

40. Andersen CL, Jensen JL, Orntoft TF. Normalization of real-time quantitative reverse transcription-PCR data: a model-based variance estimation approach to identify genes suited for normalization, applied to bladder and colon cancer data sets. Cancer Res. 2004;64(15): 5245-5250.

41. Jain A, Barve A, Zhao Z, Jin W, Cheng K. Comparison of avidin, neutravidin, and streptavidin as nanocarriers for efficient siRNA delivery. Mol Pharm. 2017;14(5):1517-1527.

42. Dong YD, Tchung E, Nowell C, et al. Microfluidic preparation of drug-loaded PEGylated liposomes, and the impact of liposome size on tumour retention and penetration. J Liposome Res. 2017;29(1):1-9.

43. Granfeldt A, Hvas CL, Graversen JH, et al. Targeting dexamethasone to macrophages in a porcine endotoxemic model. Crit Care Med. 2013;41(11):e309-e318.

44. Graversen JH, Svendsen P, Dagnaes-Hansen F, et al. Targeting the hemoglobin scavenger receptor CD163 in macrophages highly increases the anti-inflammatory potency of dexamethasone. Mol Ther 2012;20(8):1550-1558.

45. Ramalho MJ, Loureiro JA, Gomes B, Frasco MF, Coelho MA, Pereira MC. PLGA nanoparticles as a platform for vitamin D-based cancer therapy. Beilstein J Nanotechnol. 2015;6:1306-1318.

46. Lameijer MA, Tang J, Nahrendorf M, Beelen RH, Mulder WJ. Monocytes and macrophages as nanomedicinal targets for improved diagnosis and treatment of disease. Expert Rev Mol Diagn. 2013;13(6):567-580.

47. Jain RK, Stylianopoulos T. Delivering nanomedicine to solid tumors. Nat Rev Clin Oncol. 2010;7(11):653-664.

48. Wynn TA, Chawla A, Pollard JW. Macrophage biology in development, homeostasis and disease. Nature. 2013;496(7446):445-455.
49. Murray PJ, Wynn TA. Protective and pathogenic functions of macrophage subsets. Nat Rev Immunol. 2011;11(11):723-737.

50. Kristiansen M, Graversen JH, Jacobsen C, et al. Identification of the haemoglobin scavenger receptor. Nature. 2001;409(6817):198-201.

51. Sanseverino I, Rinaldi AO, Purificato C, et al. CCL2 induction by 1,25(OH)2D3 in dendritic cells from healthy donors and multiple sclerosis patients. J Steroid Biochem Mol Biol. 2014;144(Pt A):102-105.

52. Wang YC, Hsieh CC, Kuo HF, et al. Effect of vitamin D3 on monocyte chemoattractant protein 1 production in monocytes and macrophages. Acta Cardiol Sin. 2014;30(2):144-150.

53. Tokuda N, Mizuki N, Kasahara M, Levy RB. 1,25-dihydroxyvitamin D3 down-regulation of HLA-DR on human peripheral blood monocytes. Immunology. 1992;75(2):349-354.

54. Rigby WF, Waugh M, Graziano RF. Regulation of human monocyte HLA-DR and CD4 antigen expression, and antigen presentation by 1,25-dihydroxyvitamin D3. Blood. 1990;76(1):189-197.

55. Almerighi C, Sinistro A, Cavazza A, Ciaprini C, Rocchi G, Bergamini A. 1Alpha,25-dihydroxyvitamin D3 inhibits CD40L-induced pro-inflammatory and immunomodulatory activity in human monocytes. Cytokine. 2009;45(3):190-197.

56. Heine G, Niesner U, Chang HD, et al. 1,25-dihydroxyvitamin $\mathrm{D}(3)$ promotes IL-10 production in human B cells. Eur J Immunol. 2008;38(8):2210-2218.

57. Penna G, Adorini L. 1,25-dihydroxyvitamin D3 inhibits differentiation, maturation, activation, and survival of dendritic cells leading to impaired alloreactive T cell activation. J Immunol. 2000;164(5):2405-2411.

58. Sercombe L, Veerati T, Moheimani F, Wu SY, Sood AK, Hua S. Advances and challenges of liposome assisted drug delivery. Front Pharmacol. 2015;6:286.

59. Kraft JC, Freeling JP, Wang Z, Ho RJ. Emerging research and clinical development trends of liposome and lipid nanoparticle drug delivery systems. J Pharm Sci. 2014;103(1):29-52.

60. Moghimi SM, Moghimi M. Enhanced lymph node retention of subcutaneously injected IgG1-PEG2000-liposomes through pentameric IgM antibody-mediated vesicular aggregation. Biochim Biophys Acta. 2008;1778(1):51-55.

61. Pridgen EM, Alexis F, Kuo TT, et al. Transepithelial transport of Fctargeted nanoparticles by the neonatal fc receptor for oral delivery. Sci Transl Med. 2013;5(213):213ra167. 


\section{Supplementary materials}

A

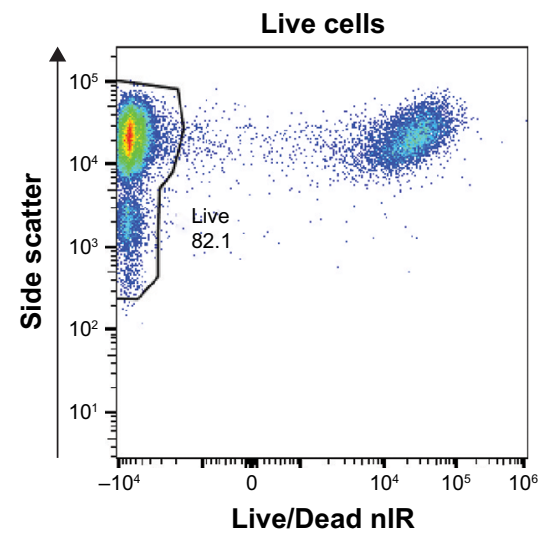

\section{Gating strategy}

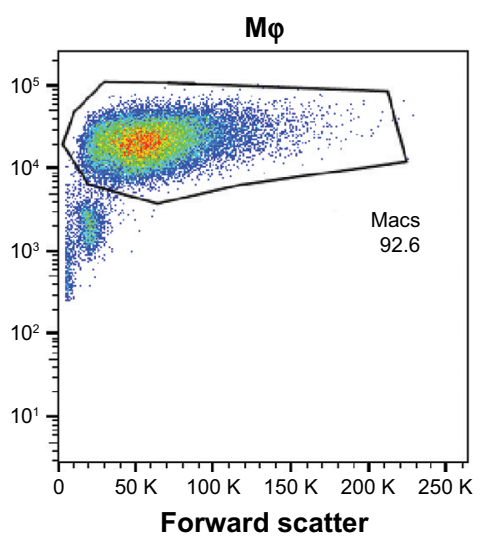

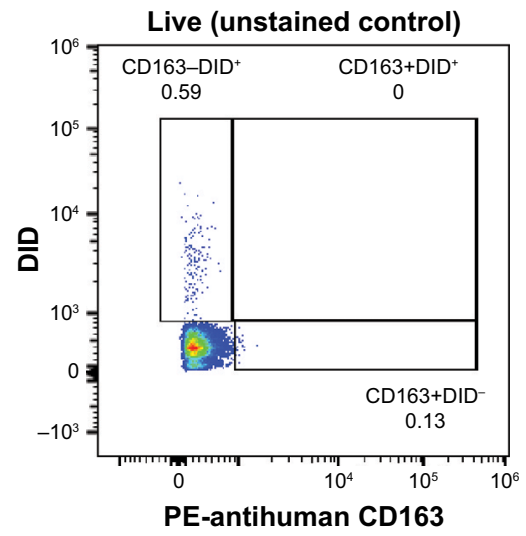
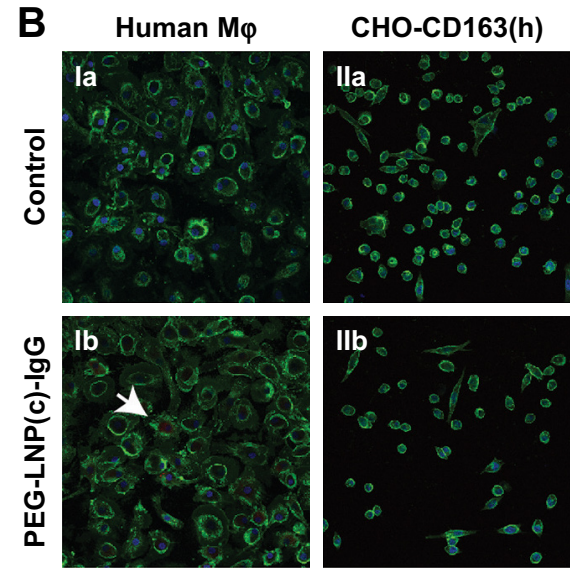

CHO-MOCK(h)
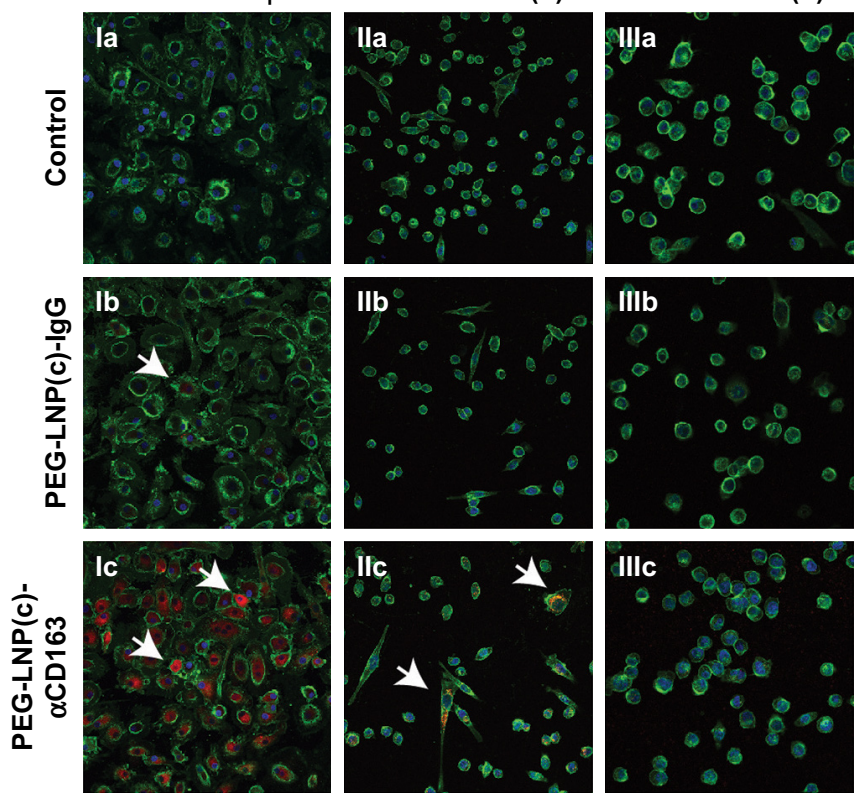

Figure SI (Continued) 


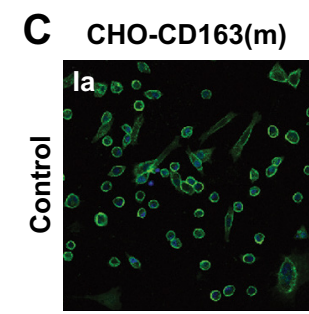

\section{CHO-MOCK $(\mathrm{m})$}
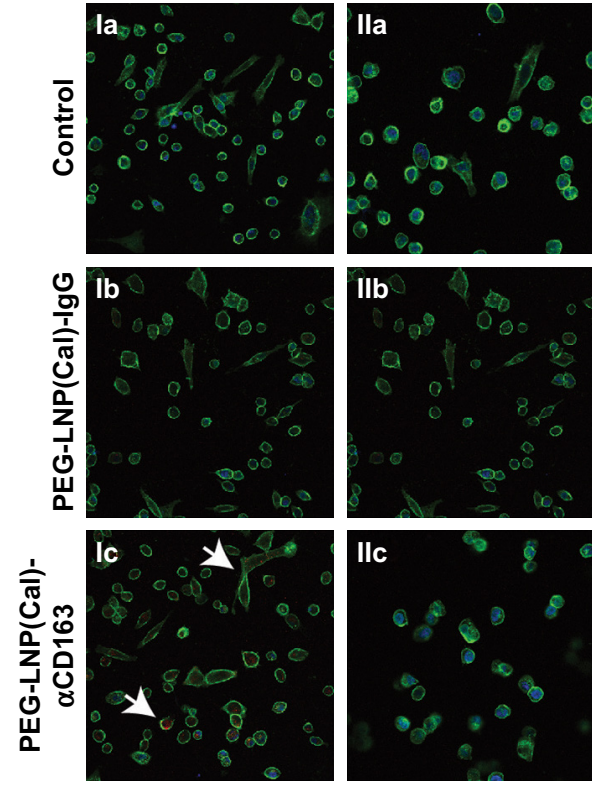
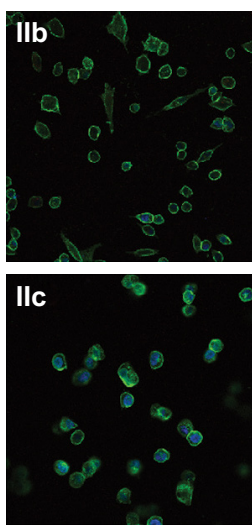

CHO-CD163(m)
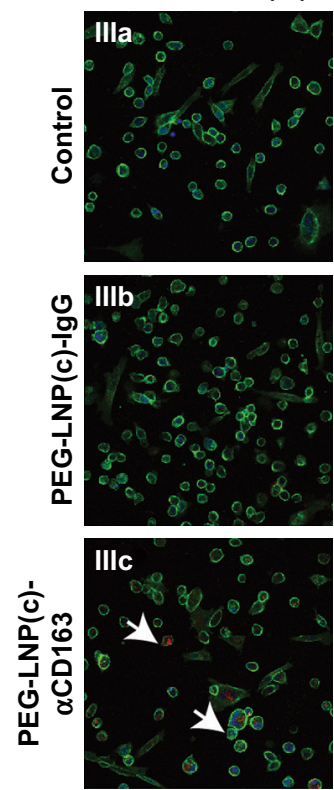

CHO-MOCK(m)
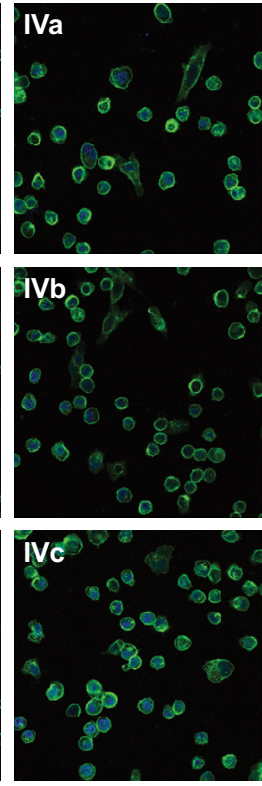

Figure SI Flow cytometry gating strategy and uptake of nIR IgG- and CDI63-targeted PEG-LNPs by M $\varphi$ and CHO-CDI63 transfected cells visualized by confocal microscopy. (A) Gating strategy: M $\varphi$ were stained with Live/Dead nIR and live cells (cell viability $>75 \%$ ) were gated. M $\varphi$ were gated using a forward/side scatter plot and [CDI63+DID-], [CDI63-DID+], and [CDI63+DID ] gates were placed according to unstimulated (Live/Dead stained) M $\varphi$ blank controls. (B) M $\varphi$ (la-Ic), human CDI63transfected CHO cells (Ila-llc), and control CHO-MOCK(h) (Illa-lllc) were stimulated for 24 hours with either control medium, 25 nM DID PEG-LNP(c)-lgG, or 25 nM DID PEG-LNP(c)- $\alpha$ CDI 63 (DID: red). Cell membranes were stained with wheat germ agglutinin Alexa Flour 488 (green), and cell nuclei were counterstained with DAPI (blue). White arrows indicate the uptake of DID PEG-LNP(c)-IgG and DID-PEG-LNP(c)- $\alpha$ CDI63. (C) Murine CDI63-transfected CHO cells and control CHO-MOCK(m) cells were treated with IgG- and CDI63-targeted PEG-LNP(Cal) (la-lc, Ila-Ilc) or lgG- and CDI63-targeted PEG-LNP(c) (IIla-IIlc, IVa-IVc). Murine CDI63-transfected CHO cells and control $\mathrm{CHO}-\mathrm{MOCK}(\mathrm{m})$ cells were stained as described for human $\mathrm{CHO}$ cells.

Abbreviations: M $\varphi$, macrophages; nIR, near-infrared; LNPs, lipid nanoparticles; LNP(c), conventional empty LNPs; PEG, polyethylene glycol; PEG-LNP(Cal), calcitriol PEGylated lipid nanoparticles. 

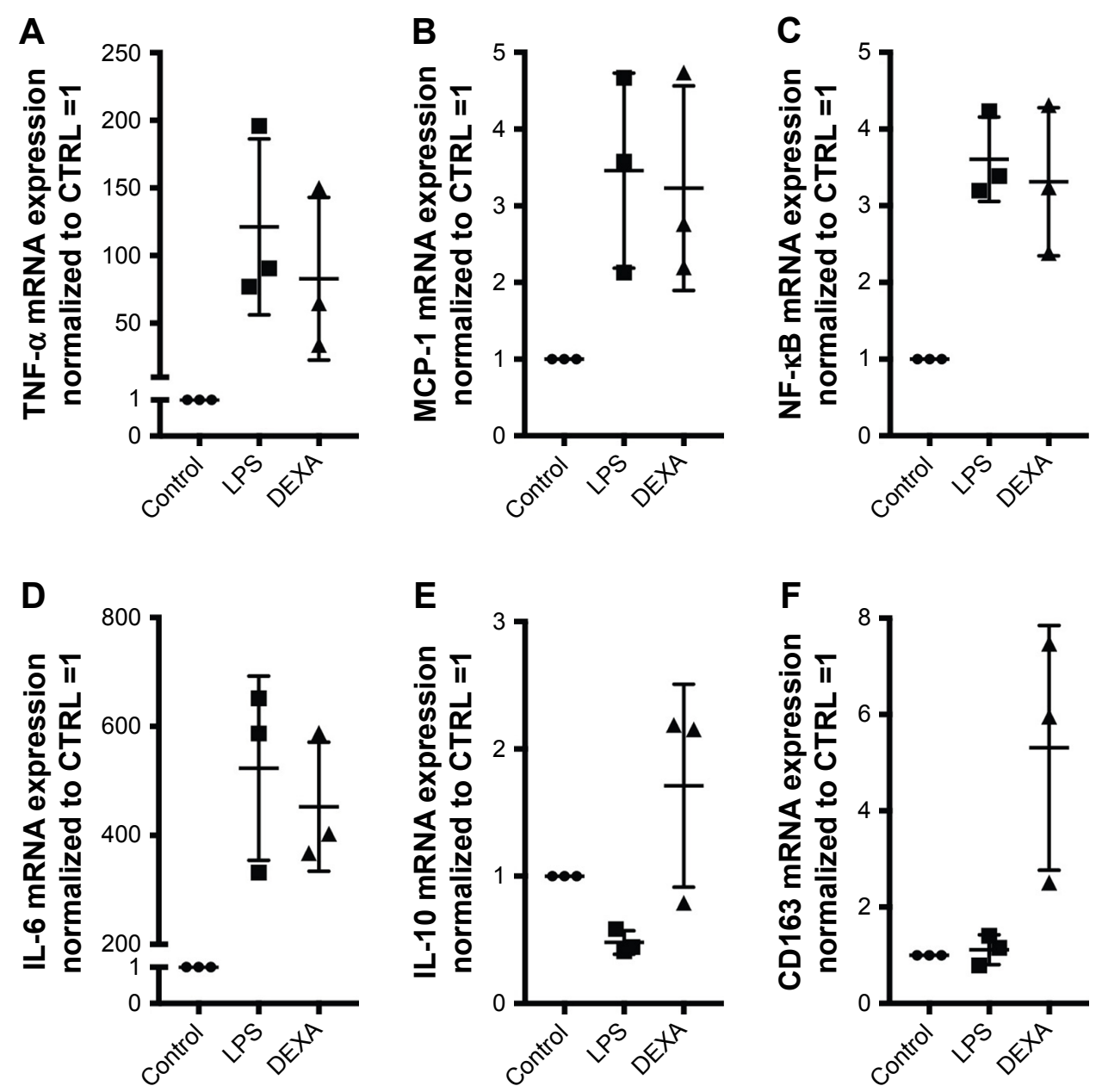

Figure S2 mRNA gene expression analyses of target genes (TNF- $\alpha$, MCP-I, NF- $\mathrm{KB}$, IL-6, IL-I0, and CDI63). mRNA target gene expressions of untreated M $\varphi$, M $\varphi$ treated with LPS (I $\mu \mathrm{g} / \mathrm{mL}$ for 4 hours), and LPS-induced M $\varphi$ treated with dexamethasone (10 $\mu \mathrm{M}$ for 24 hours). Target gene expression levels were normalized to the stable housekeeping gene GAPDH, and the resulting mRNA ratios were normalized to untreated control M $\varphi$ and given the value I. Controls for (A) TNF- $\alpha$, (B) MCP-I, (C) NF- KB, (D) IL-6, (E) IL-I0, and (F) CDI63.

Abbreviations: M $\varphi$, macrophages; TNF- $\alpha$, tumor necrosis factor-alpha; MCP-I, monocyte chemoattractant protein; NF, nuclear factor; IL, interleukin; LPS, lipopolysaccharide; DEXA, dexamethasone; CTRL, control.

\section{Publish your work in this journal}

The International Journal of Nanomedicine is an international, peerreviewed journal focusing on the application of nanotechnology in diagnostics, therapeutics, and drug delivery systems throughout the biomedical field. This journal is indexed on PubMed Central, MedLine, CAS, SciSearch ${ }^{\circledR}$, Current Contents ${ }^{\circledR} /$ Clinical Medicine,
Journal Citation Reports/Science Edition, EMBase, Scopus and the Elsevier Bibliographic databases. The manuscript management system is completely online and includes a very quick and fair peer-review system, which is all easy to use. Visit http://www.dovepress.com/ testimonials.php to read real quotes from published authors. 